\title{
Multi-criteria efficiency assessment of international biomass supply chain pathways using Data Envelopment Analysis
}

Word count: 12148 words including references and appendices

Authors: Athanasios Rentizelas ${ }^{\mathrm{a}^{*}}$, Isotilia Costa Melo ${ }^{\mathrm{b}}$, Paulo Nocera Alves Junior ${ }^{\mathrm{b}}$, Jéssica Suárez Campoli ${ }^{\mathrm{b}}$ and Daisy Aparecida do Nascimento Rebelatto ${ }^{\mathrm{b}}$.

a Department of Design Manufacture and Engineering Management, University of Strathclyde, 75 Montrose Street, G1 1XJ, Glasgow, United Kingdom

${ }^{b}$ Department of Production Engineering, USP - University of São Paulo, EESC - São Carlos Engineering School, Av. Trabalhador são-carlense, 400 CEP 13566-590, São Carlos - SP, Brazil

* Corresponding author. E-mail: athanasios.rentizelas@strath.ac.uk

Most European countries have committed to ambitious emissions reduction goals. Energy generation in particular is responsible for more than $30 \%$ of global emissions, where significant focus has been placed on renewable energy generation, including biomass. On the one hand, there are countries, like the UK, where the biomass stock is insufficient to meet the demand; on the other hand, there are countries, like Brazil, where the stock significantly exceeds the demand. To promote a natural symbiosis, it is necessary to take on the challenge of transporting biomass through long distances in an environmentally and economically efficient manner. This paper aims to assess the efficiency of alternative pathways of international biomass supplychains. The alternatives involve different biomass origin regions, transportation modes, export ports and processing technologies, including torrefaction. Data Envelopment Analysis (DEA) has been used for the first time to assess the efficiency of the alternative biomass supply chain pathways in a Latin American context, considering multiple-criteria relating to economic and environmental performance simultaneously, such as the biomass delivered cost, the environmental impact and the fossil energy consumption. Additionally, a sensitivity analysis was performed to analyse the robustness of the results under uncertainty in parameter values. The DEA approach presented can assist the process of planning biomass sourcing and improve decision-making under multiple decision criteria. The results can support medium- and longterm strategic decisions for decision- and policy-makers.

Keywords: Efficiency assessment; Data Envelopment Analysis (DEA); International Supply Chain; Biomass; Torrefaction; Brazil. 


\section{Introduction}

Many countries around the world have committed to reduce Greenhouse Gas (GHG) emissions by increasing the share of renewable energy generation. Biomass is considered as one of the main energy sources to support this process. As an example, the European Union (EU) has committed to $20 \%$ renewable energy by 2020 , while almost $51 \%$ of the increase from the 2014 levels is envisaged to be achieved using biomass (European Commission, 2015). In a similar vein, the United Kingdom (UK) 2020 target for 15\% renewable energy is expected to require half of the increase from the 2013 actual level of $5.2 \%$ to be achieved using biomass (Department of Energy \& Climate Change, 2011). Biomass is currently being used for electricity generation, heating, or CHP (Combined Heat and Power generation).

Although biomass is expected to contribute significantly to achieving these targets, it is a resource of limited availability within the UK and the EU in general: It is estimated that $70 \%$ $87 \%$ of the UK biomass requirements in 2030 will be covered by imported biomass, due to insufficient domestic sources (Department of Energy \& Climate Change, 2012). Considering that most Western European countries face a similar situation with limited domestic biomass supply on the one hand and continuously increasing biomass needs on the other, it is evident that satisfying those needs will require significant international sourcing of biomass from locations beyond Europe.

As a matter of fact, academics have indeed identified this need lately and focused their research on international biomass supply chains between countries with high biomass availability and various European destinations. Some researchers have focused on the technoeconomic aspects of various biomass supply chain configurations originating from Scandinavia (Svanberg et al., 2013), Latin America (eucalyptus) (Uslu et al., 2008), or Eastern Europe to Western Europe (energy crops and forestry residues) (Hamelinck et al., 2005), Mozambique to Netherlands (eucalyptus and switchgrass) (Batidzirai et al., 2014) and Malaysia to UK (Palm Kernel Shells - PKS) (Rentizelas and Li, 2016). Researchers have also focused on the GHG effects and energy analysis of the respective supply chain from Malaysia (PKS) and Canada (wood pellets) to Netherlands (Damen and Faaij, 2006). In terms of current industrial practices, biomass is commercially sourced primarily from United States (US), Canada and Eastern Europe for use in Western Europe. The biomass transported is mainly forest residues, in the form of wood pellets or wood chips (Uslu et al., 2008). 
Most researchers have examined international or long-distance biomass supply chains with one specific origin and destination locations and a specific supply chain configuration. Few researchers have examined alternative biomass supply chain configurations from the same origin to the same destination: Uslu et al. (2008) is one example of several different technological configurations in terms of the pre-processing of biomass in the origin country, examining the cases of pelletisation, torrefaction, torrefaction with pelletisation and pyrolysis. Hamelinck et al. (2005) adopted a similar approach but for two origin locations (Latin America and Eastern Europe). Similarly, Batidzirai et al. (2014) have examined the potential for biomass transportation between two locations in Mozambique to Netherlands, using two pre-treatment technologies.

However, the abovementioned studies have not considered the potential for alternative transportation means alongside the various pre-processing technologies. Furthermore, although these studies have provided detailed calculations about criteria such as the cost, energy use and $\mathrm{CO}_{2}$ emissions of alternative supply chain configurations, they do not provide a structured way to identify the best configuration overall considering all three criteria simultaneously. Hence, the need was identified for providing a decision-support tool to facilitate decisions on supply chain design, based on the real multi-criteria nature of such decisions.

In reality, a potential biomass user located in Western Europe would face a dilemma of selecting among various alternative origin locations to source the biomass from; and there will often be more than one options regarding not only the pre-processing technology, but also the transportation means to use, leading to multiple possible configurations (pathways) of the respective supply chain. Furthermore, biomass suppliers and users need to demonstrate that the long-distance biomass supply chains do not have a significant environmental impact that reduces the sustainability of biomass as a renewable fuel. This means that decision makers need to consider the supply chain environmental impact alongside the traditionally considered cost, leading to a more complex, multi-criteria decision process.

Within this frame, the present study aims to address these issues by considering international wood biomass supply chains from South America to the UK, assessing the efficiency of alternative supply chain pathways simultaneously in terms of cost, environmental impact and fossil energy input, while integrating also alternative modes of transportation where they exist. This paper aims to contribute as a tool for selecting the most efficient biomass supply chain design when decisions about sourcing biomass internationally are to be made. It also aims to contribute in assessing specifically the potential for international wood biomass 
transportation between Brazil and the UK, which has not been examined in the literature up to now.

\section{Literature Review}

There have been various methods applied in academia for modelling and/or optimization in the context of sustainable and green supply chains. Qorri et al. (2018) analysed 104 peer-reviewed papers in sustainable supply chains and concluded that the application of multi-criteria methods, such as Data Envelopment Analysis (DEA), Analytical Hierarchy Processes (AHP), and linear programming, is increasing in this field.

There is a large body of literature applying MILP (Mixed Integer Linear Programming) methods for tactical or strategic level of decision making in biomass supply chains, as it can be concluded by the relevant literature reviews of De Meyer et al. (2014) and Mafakheri and Nasiri (2014). Just to name a few, $\mathrm{Ng}$ et al. (2013) and ten Kate et al. (2017) have applied MILP to design a rubber seed to biodiesel supply network in Malaysia and in Indonesia respectively, while Sharifzadeh et al. (2015) investigated the hardwood to bio-fuel production in the UK. In all the above mentioned cases, the purpose was to identify a single optimal supply chain design solution, with the single objective of profit maximisation. In other cases, such as in Zhang and Jiang (2016), a multi-objective approach has been adopted, aiming to minimise emissions and unused waste additionally to maximising the profit, while still identifying a single optimal solution. How and Lam (2018) proposed combining linear programming with PCA (Principal Component Analysis) and AHP for reducing the redundancy of data series of biomass networks. The authors applied the proposed approach to a case study in Malaysia, where 13 variables were reduced to 3. There have also been instances where MILP has been used for multi-period models, such as in Ahn et al. (2015), who modelled a microalgae biomass-tobiodiesel supply chain network, considering resource, demand, and technology constraints over a long-term planning horizon, with the single objective of minimising the total cost. Therefore, it can be concluded that MILP has been widely applied in biomass supply chain modelling, adopting a single or multiple objectives, always identifying a single optimal configuration. In this respect, the methods analysed differ from the present proposition, as they are not able to provide a ranking of a large number of supply chain configuration alternatives based on their efficiency performance against multiple criteria.

The only known examples of research applying DEA specifically to biomass supply chains are Grigoroudis et al. (2014) and Babazadeh et al. (2017). Both papers integrated DEA to linear programming methods, the former is recursive (RDEA) and the latter unified (UDEA). 
Both papers applied DEA to a multi-echelon and multi-stage supply chain, though Babazadeh et al. (2015) also considered a multi-period problem. Grigoroudis et al. (2014) focused on cost reduction and did not consider different modes of transportation as alternatives, while Babazadeh et al. (2017) considered road and rail transportation options. Both papers though do not consider environmental aspects.

Relating the DEA-based papers to the present study, it can be concluded that their aim is to support supply network design at a strategic level by identifying one optimum design in terms of cost only as an objective and additionally technical efficiency in the form of throughput for Grigoroudis et al. (2014), and not to examine and compare alternative pathways using many criteria that also include environmental impact. They are also applied to local or national supply chains, therefore not examining the long-distance, international supply chain context examined in the present study.

It can therefore be concluded that the novelty of the present study lies also in the application for the first time of DEA for multi-criteria decision making for international biomass supply chains where several alternative pathways are possible, including the direct environmental impact in the set of criteria.

\section{Methodology}

The key method applied in the study is DEA, in order to assess and rank the efficiency of several alternative biomass supply chain pathways (which are the Decision Making Units DMUs - in this study) against a set of criteria.

When applying DEA, the first recommended step is to have a clear vision of the "process" under analysis to drive the choice of inputs and outputs of a model (Cook et al., 2014). It is important to critically examine where the DMUs operate, as well as the alignment of the choice of variables to the objective of the analysis and the reliability of the data.

The second step highlights the decision whether to aggregate factors, which depends strongly on the objective of the analysis and may involve statistical analysis such as correlations, PCA and/or linear regressions.

The third step consists of trials of different DEA models and configurations, followed by the assessment of the coherence and utility of the results, based on the objective of the analysis (Adler and Golany, 2007). 
Finally, Greco et al. (2018) emphasized that an index creation without a robustness analysis may lead to fallacious interpretations. Therefore, sensitivity analysis should be undertaken as a fourth step for a successful DEA model application.

In line with the above, the adopted methodology in this study includes the following steps:

- Definition of the scenarios and DMUs to be investigated (discussed in the Case Study Description section).

- Data collection, aggregation, variable definition, and correlation analysis.

- Investigation of DEA model configurations, considering both constant and variable scale, and two different approaches for treating emissions as undesirable output.

- Robustness analysis of the results through the method of super-efficiency.

- Tie-breaking method of composite-index.

The adopted DEA methodological process flowchart is presented visually in Figure 1:

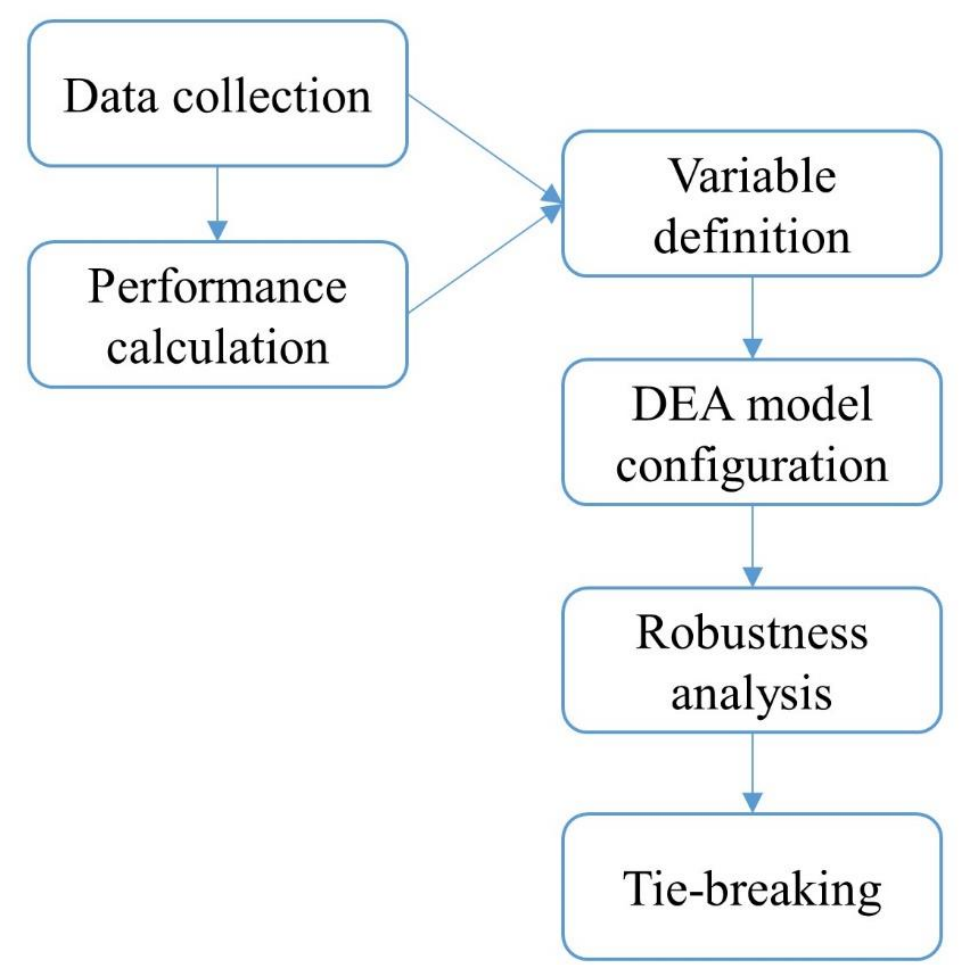

Figure 1 DEA methodological process flowchart.

\subsection{Data collection, performance calculation, and variables definition}

In the present study, it was decided to work with three variables expressing the decision criteria that were of primary interest in the supply chain: total costs (TC), total energy 
consumption (TEC), and total $\mathrm{CO}_{2}$ emissions equivalent (TE). TC and TEC were considered as inputs and TE as an undesirable output. These variables were identified as the key decision criteria in the biomass energy sector by combining the literature, practitioner and context information.

TC are a traditional key consideration as they affect directly the feasibility of any profit making business; TE represents the sustainability of the supply chain in terms of contribution to global warming; and the TEC is another sustainability indicator, as a high fossil fuel energy input would limit the renewable nature of the biomass as a fuel.

The values of TC, TEC, and TE for each investigated pathway can be found in Table 9 in the Appendix. They were calculated as the sum of the same variables related to transportation and to processing of materials (pelletisation and/or torrefaction), according to Equations (1) to (3):

$$
\begin{aligned}
& \mathrm{TC}=\mathrm{T}_{\mathrm{C}}+\mathrm{P}_{\mathrm{C}} \\
& \mathrm{TEC}=\mathrm{T}_{\mathrm{EC}}+\mathrm{P}_{\mathrm{EC}} \\
& \mathrm{TE}=\mathrm{T}_{\mathrm{E}}+\mathrm{P}_{\mathrm{E}}
\end{aligned}
$$

Where:

$\mathrm{T}_{\mathrm{C}}$ : Transportation costs.

$\mathrm{P}_{\mathrm{C}}$ : Process costs.

$\mathrm{T}_{\mathrm{EC}}$ : Transportation energy consumption.

$\mathrm{P}_{\mathrm{EC}}$ : Process energy consumption.

$\mathrm{T}_{\mathrm{E}}$ : Transportation emissions.

$\mathrm{P}_{\mathrm{E}}$ : Process emissions.

All variables of each supply chain stage were calculated for $1 \mathrm{t}$ of black biomass pellets (torrefied and pelletised) delivered at the final use destination (see Figure 2 - Case Study Description). All monetary values were calculated in US\$.

Variables related to transportation $\left(\mathrm{T}_{\mathrm{C}}, \mathrm{T}_{\mathrm{EC}}\right.$ and $\left.\mathrm{T}_{\mathrm{E}}\right)$ in each pathway were calculated considering the Transported Mass $\left(\mathrm{TM}_{\mathrm{i}}\right)$ of each stage $i$ that corresponds to $1 \mathrm{t}$ of black pellet biomass delivered to the end user. It should be noted that a $1 \%$ of mass loss was assumed to occur at each stage of transportation, according to Batidzirai et al., (2014). 
The truck and train capacity were assumed equal to that of standard vehicles of the EcoTransIT Methodology (2014) (Table 1) that was used for transportation-related calculations on energy consumption and emissions.

A key parameter affecting transportation costs is the material density. The density and moisture levels of wood logs, white pellets and torrefied (black) pellets are $600 \mathrm{~kg} / \mathrm{m}^{3}$ and $55 \%$, $650 \mathrm{~kg} / \mathrm{m}^{3}$ and 8,5\% and $800 \mathrm{~kg} / \mathrm{m}^{3}$ and 5\% respectively (Ehrig and Behrendt, 2013; Hamelinck et al., 2005; Tree Functional Attributes and Ecological Database, 2019).

Table 1 Parameters used for Energy Consumption and Emissions in EcoTransIT.

\begin{tabular}{lcc}
\hline EcoTransIT & Road Freight & Rail Freight \\
Parameters & Extended & Extended \\
\hline Input mode & 100 & 100 \\
Amount & Bulk and Unit & Bulk and Unit \\
Unit & Loads (t) & Loads $(\mathrm{t})$ \\
& Average goods & Average goods \\
Type & 10 & 10 \\
t/TEU & Truck & Train \\
Transport mode & $26-40 \mathrm{t}$ & Average Train $(1,000 \mathrm{t})$ \\
Vehicle type & EURO5 & Diesel \\
Emission standard & $100 \%$ & $100 \%$ \\
Load factor & $50 \%$ & $50 \%$ \\
Empty Trip Factor & $\mathrm{UN} / \mathrm{LOCODE}$ & $\mathrm{UN} / \mathrm{LOCODE}$ \\
Destination & &
\end{tabular}

In this regard, transportation costs $\left(\mathrm{T}_{\mathrm{C}}\right)$ for a certain pathway are the sum of all transportation costs of each of the transportation stages, where truck and train transportation could be used in more than one instance, noted as $i$ and $j$ respectively Equation (4):

$$
\mathrm{T}_{\mathrm{C}}=\sum_{\text {truck stages }}\left(\mathrm{T}_{\mathrm{C} \mathrm{i}} / \mathrm{TM}_{\mathrm{i}}\right)+\sum_{\text {train stages }}\left(\mathrm{T}_{\mathrm{C}} / \mathrm{TM}_{\mathrm{j}}\right)+\left(\mathrm{T}_{\mathrm{C} \text { ship }}+\text { Port fees }\right) / \mathrm{TM}_{\text {ship stage }}
$$

The truck and train freight costs $\left(\mathrm{T}_{\mathrm{Ci}}\right.$ and $\left.\mathrm{T}_{\mathrm{Cj}}\right)$ for Brazil were obtained from the ESALQ-LOG database, the official agricultural logistics cost database (SIFRECA - ESALQLOG, 2016). The train freight costs for the UK were obtained from industry sources. All monetary values were converted to US\$ considering the average yearly exchange rate (OFX, 2017).

Regarding the shipping stage in particular, the cost, energy and emissions have been analytically calculated based on Rentizelas and Li (2016). A Handymax bulk carrier with capacity of $45,000 \mathrm{t}$ and $56,250 \mathrm{~m}^{3}$ has been assumed to be used in all cases, as this ship type 
usually has self-loading and unloading capability on-board and therefore can load also from smaller ports that do not have the appropriate loading infrastructure, as may be the case with some of the smaller Brazilian ports. Based on the weight to volume ratio, the cargo density of the ship is $800 \mathrm{~kg} / \mathrm{m}^{3}$; therefore, the volume is the restrictive factor in the sea transportation stage, leading to suboptimal utilization of the ship capacity, apart from the case of torrefied pellets where the material density is marginally equal to the cargo density.

The ship speed was assumed to be $12.5 \mathrm{kn}$. The ship is assumed to be travelling $95 \%$ of the time in non-ECA (Emission Control Area) routes, using Heavy Fuel Oil (HFO), and the rest of the time in ECA routes using Marine Gas Oil (MGO), as lower Sulphur content fuel should be used in the latter case. For the routes considered in this study, only the part of English Channel and North Sea would fall under ECA regulations. Since the sea transportation stage has been found to be one of the major cost, energy use and emissions factors in long-distance biomass supply chains in the literature (Batidzirai et al., 2014), the sea transportation cost has been calculated analytically in this study as a time charter by adding a daily charter rate (US\$8,000), the fuel cost and other major operational costs (port fees). The port fees in Brazil were retrieved from the official data from National Waterway Transportation Agency (National Waterway Transportation Agency, 2017) and also converted to US\$ considering the average yearly exchange rate (OFX, 2017). In parallel to transportation costs, transportation energy consumption $\left(\mathrm{T}_{\mathrm{EC}}\right)$ and transportation $\mathrm{CO}_{2}$ equivalent emissions $\left(\mathrm{T}_{\mathrm{E}}\right)$ were calculated according to Equations (5) and (6):

$$
\begin{aligned}
& \mathrm{T}_{\mathrm{EC}}=\sum_{\text {truck stages }}\left(\mathrm{T}_{\mathrm{EC}_{\mathrm{i}}} / \mathrm{TM}_{\mathrm{i}}\right)+\sum_{\text {train stages }}\left(\mathrm{T}_{\mathrm{EC}_{\mathrm{j}}} / \mathrm{TM}_{\mathrm{j}}\right)+\mathrm{T}_{\mathrm{EC} \text { ship }} / \mathrm{TM}_{\text {ship stage }} \\
& \mathrm{T}_{\mathrm{E}}=\sum_{\text {truck stages }}\left(\mathrm{T}_{\mathrm{E}_{\mathrm{i}}} / \mathrm{TM}_{\mathrm{i}}\right)+\sum_{\text {train stages }}\left(\mathrm{T}_{\mathrm{E}_{\mathrm{j}}} / \mathrm{TM}_{\mathrm{j}}\right)+\mathrm{T}_{\mathrm{E} \text { ship }} / \mathrm{TM}_{\text {ship stage }}
\end{aligned}
$$

The truck and train energy consumption $\left(\mathrm{T}_{\mathrm{EC}_{\mathrm{i}}}\right.$ and $\left.\mathrm{T}_{\mathrm{EC}_{\mathrm{j}}}\right)$ and emissions $\left(\mathrm{T}_{\mathrm{E}_{\mathrm{i}}}\right.$ and $\left.\mathrm{T}_{\mathrm{E}_{\mathrm{j}}}\right)$ for each transportation stage were calculated using a dedicated software (EcoTransIT, 2016), considering the mode of well-to-wheel (WTW) analysis. Table 1 presents the main input parameters in EcoTransIT.

Biomass processing parameters were derived from literature sources and are shown in Table 2. It should be noted that a torrefaction plant in isolation (without pelletisation after torrefaction) has not been considered in this study, as even in the cases where the torrefaction process is occurring using white pellets as inputs, the pellets could lose their handling 
properties after torrefaction and would need pelleting again to ensure suitability for further transportation or other logistical activities.

Table 2 Biomass processing assumptions.

\begin{tabular}{|c|c|c|c|c|}
\hline \multicolumn{3}{|c|}{ Torrefaction \& Pelleting plant } & \multicolumn{2}{|c|}{ Pelleting plant } \\
\hline \multicolumn{3}{|c|}{ Both processes co-located - output: black pellets } & \multicolumn{2}{|c|}{ Output: white pellets } \\
\hline Parameter & Assumptions & Sources & Assumptions & Sources \\
\hline Reference capacity & $\begin{array}{l}\text { 200,000 t Dry } \\
\text { substance/year } \\
\text { (output) }\end{array}$ & $\begin{array}{l}\text { (Svanberg et } \\
\text { al., 2013) }\end{array}$ & $\begin{array}{l}\text { 200,000 t Dry } \\
\text { Substance/year } \\
\text { (output) }\end{array}$ & $\begin{array}{l}\text { (Uslu et al., } \\
\text { 2008) }\end{array}$ \\
\hline $\begin{array}{l}\text { Capital expenditure } \\
\text { for reference } \\
\text { capacity }\end{array}$ & 60.5 M US\$ & $\begin{array}{l}\text { (Svanberg et } \\
\text { al., 2013) }\end{array}$ & $9.2 \mathrm{M}$ US\$ & $\begin{array}{l}\text { (Uslu et al., } \\
\text { 2008) }\end{array}$ \\
\hline $\begin{array}{l}\text { Maintenance cost for } \\
\text { reference capacity }\end{array}$ & $\begin{array}{l}2.0 \% \text { of capital } \\
\text { expenditure per year }\end{array}$ & $\begin{array}{l}\text { (Svanberg et } \\
\text { al., 2013) }\end{array}$ & $\begin{array}{l}5.0 \% \text { of capital } \\
\text { expenditure per year }\end{array}$ & $\begin{array}{l}\text { (Uslu et al., } \\
\text { 2008) }\end{array}$ \\
\hline $\begin{array}{l}\text { Personnel required } \\
\text { for reference } \\
\text { capacity }\end{array}$ & 24.0 & $\begin{array}{l}\text { (Svanberg et } \\
\text { al., 2013) }\end{array}$ & $\begin{array}{l}\text { Assumed the same as } \\
\text { in torrefaction }\end{array}$ & \\
\hline Scale factor & 0.7 & $\begin{array}{l}\text { (Svanberg et } \\
\text { al., 2013) }\end{array}$ & 0.7 & $\begin{array}{l}\text { (Uslu et al., } \\
\text { 2008) }\end{array}$ \\
\hline $\begin{array}{l}\text { Energy input in } \\
\text { process }\end{array}$ & $\begin{array}{c}193.0 \mathrm{kWh} \\
\text { electricity per } \\
\text { produced } \mathrm{t}\end{array}$ & $\begin{array}{l}\text { (Batidzirai et } \\
\text { al., 2014) }\end{array}$ & $\begin{array}{l}22.0 \mathrm{kWh} \text { electricity } \\
\text { per produced } \mathrm{t}\end{array}$ & $\begin{array}{l}\text { (Batidzirai et } \\
\text { al., 2014) }\end{array}$ \\
\hline
\end{tabular}

The investment cost (I) was directly considered for the processing facilities (pelletisation or torrefaction \& pelletisation), in the scenarios where these do not currently exist. The capital expenditure for a reference capacity (Table 2) was corrected for inflation, using the CPI (Consumer Price Index) in Great Britain and IGP-M (Índice Geral de Preços do Mercado, General Index of Market Prices) in Brazil (Worldwide Inflation Data, 2019). Annual costs, $\left(I_{a}\right)$ are calculated using the formula in Equation (7) (Batidzirai et al., 2014):

$$
\mathrm{I}_{\mathrm{a}}=\mathrm{I} \cdot \frac{\mathrm{i}}{\left(\mathrm{i}-(1+\mathrm{i})^{-\mathrm{N}}\right.}
$$

Where:

I: the total investment requirement (Table 2).

i: discount rate (\%) - assumed equal to SELIC (Sistema Especial de Liquidação e Custódia, Special System of Settlement and Custody), the Brazilian basic interest rate (Bacen - Central Bank of Brazil, 2019).

$\mathrm{N}$ : the lifetime of the facility (years) - assumed 15 years according to Svanberg et al., (2013). 
Process costs $\left(\mathrm{P}_{\mathrm{C}}\right)$ for a certain pathway is the sum of process operational costs $\left(\mathrm{P}_{\mathrm{OC}}\right)$ and, in cases where new facilities are necessary, the annual costs $\left(I_{a}\right)$, divided by the reference capacity (RC), as follows (Equation (8)):

$$
\mathrm{P}_{\mathrm{C}}=\frac{\mathrm{P}_{\mathrm{OC}} \text { pelletisation }}{\mathrm{RC}_{\text {pelletisation }}}+\frac{\mathrm{P}_{\mathrm{OC}} \text { torrefaction and pelletisation }}{\mathrm{RC}_{\text {torrefaction and pelletisation }}}+\frac{\mathrm{I}_{\mathrm{a}}}{\mathrm{RC}_{\text {torrefaction and pelletisation }}}
$$

Process operational costs $\left(\mathrm{P}_{\mathrm{Oc}_{\text {pelletisation }}}\right.$ and $\left.\mathrm{P}_{\mathrm{OC}_{\text {torrefaction and pelletisation }}}\right)$ are analytically calculated per delivered $t$, through the sum of energy input costs, labour costs, and maintenance costs (parameters of Table 2). In Brazil and in the UK, the electricity price and taxes were retrieved, respectively, from CEE Distribution (2019) and from EuroStat (2016), and the labour costs were calculated based on the Brazilian minimum salary and related taxes (Government of Brazil, 2019) and on EuroStat (2016).

The process energy consumption $\left(\mathrm{P}_{\mathrm{EC}}\right)$ was calculated as follows (Equation (9)):

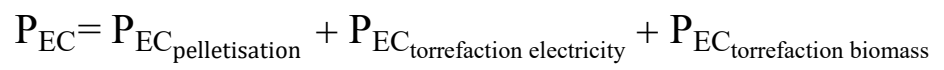

Where:

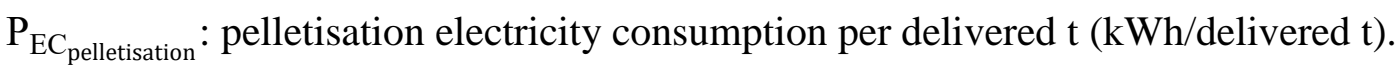

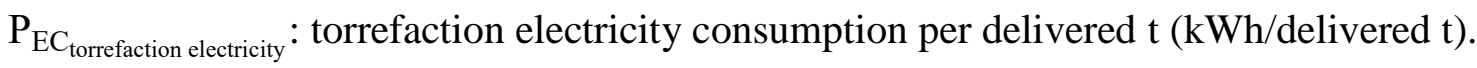

$\mathrm{P}_{\mathrm{EC}_{\text {torrefaction biomass }}}$ : torrefaction energy input, considering the biomass consumption (for drying) per delivered $\mathrm{t}(\mathrm{kWh} /$ delivered $\mathrm{t})$.

The emissions for pelletisation $\left(\mathrm{P}_{\mathrm{E}_{\text {pelletisation }}}\right)$ were calculated based on energy input on the process (Table 2) multiplied by the electricity-specific emissions factor $\left(\mathrm{kgCO}_{2 \mathrm{eq}} / \mathrm{kWh}\right)$, provided by Brander et al. (2011). The emissions for torrefaction $\left(\mathrm{P}_{\mathrm{E}_{\text {torrefaction and pelletisation }}}\right)$ were calculated based on Ehrig and Behrendt (2013), assuming that the conditions are similar to the supply chain between Canada and Europe. In this regard, process emissions $\left(\mathrm{P}_{\mathrm{E}}\right)$ were calculated as follows (Equation (10)):

$$
\mathrm{P}_{\mathrm{E}}=\mathrm{P}_{\mathrm{E}_{\text {pelletisation }}}+\mathrm{P}_{\mathrm{E}_{\text {torrefaction and pelletisation }}}
$$

In terms of DEA-related methodological considerations, Table 3 presents the correlations among variables and their significance, executed with the software STATA. Lin 
(2008) and Golany and Roll (1989) stated that for DEA analysis, it is desired that relevant variables do not virtually repeat the same information; therefore, if the correlation between a pair of outputs or between a pair of inputs is strong, one of the variables should be excluded from the analysis. This decision of excluding variables also depends on the overview of the whole process, the opinion of the specialists, the goal of the analysis or the associated application of other tools. In the present case, the correlations were not strong (the highest being 0.4052 ) with significance level below 0.15 , which was judged as acceptable. It is also desired (but not mandatory) that the inputs have a low correlation among each other, as highly correlated inputs may suggest redundancy in the model. In the present case, inputs have a low correlation, which was judged as acceptable.

Table 3 Correlations with their respective significance for the proposed variables.

\begin{tabular}{lcccc}
\hline & & Total Cost & Energy Consumption & Emissions \\
\hline Total Cost & Correlation & 1 & & \\
& Significance & & 1 & \\
\hline Energy Consumption & Correlation & -0.2839 & 0.4052 & 1 \\
& Significance & 0.0340 & 0.0019 & \\
\hline Emissions & Correlation & 0.2002 & & \\
& Significance & 0.1390 &
\end{tabular}

There are many methodological options of treating a variable in a DEA model as an 'undesirable' variable. However, a detailed discussion on this is beyond the scope of the present paper; the interested reader may refer to Hua and Bian (2007), Liu et al. (2010), Scheel (2001), and Seiford and Zhu (2002). For this context, it is relevant to mention that undesirable outputs may be considered as inputs (for the purpose of minimization) or their inverse may be considered as outputs in the DEA formulation (in this way, their maximization represents an actual value reduction). The creator of the Slack-Based Measure (SBM) DEA model stated that the treatment of undesirable outputs as outputs using a multiplicative inverse transformation (e.g. using 1/emissions as an output) in SBM model may cause distortion of the efficiency frontier at some points, because it is a non-linear transformation, and the translation (using the linear transformation $\mathrm{Y}=\mathrm{Max}_{\mathrm{emissions}}+\mathrm{Min}_{\mathrm{emissions}}-\mathrm{DMU}_{\mathrm{emissions}}$ as an output) can be used only in Variable Returns to Scale (VRS) cases (Tone, 2003). For these reasons, it was decided to investigate three possible variables configurations for the present research:

1) costs and energy as inputs, and using a multiplicative inverse transformation to treat 1/emissions (named "inverted emissions") as outputs (with variable scale). 
2) costs and energy as inputs, and using a translation (linear transformation as $\mathrm{Y}=$ $\mathrm{Max}_{\text {emissions }}+\mathrm{Min}_{\text {emissions }}-\mathrm{DMU}_{\text {emissions}}$ ) to treat emissions (named "translated emissions") as outputs, only for the VRS assumption, according to the guidelines of Seiford and Zhu (2002).

3) costs, energy and emissions as inputs, and a unitary output for all DMUs, similar to the proposition of Organisation for Economic Co-operation and Development (OECD)European Commission (2008) to CCR DEA model (CCR is acronym of the names of the model's creators: Charnes, Cooper, and Rhodes). In this case, the results with CRS (Constant Return to Scale) and VRS will be compared. To the best of the authors' knowledge, this case is the first application of an SBM model with a unitary output for an index construction.

\subsection{Investigation of DEA model configurations: constant and variable returns to scale}

The software MATLAB was used to execute the SBM DEA model. The choice of the model (SBM) was informed by its characteristic of simultaneously maximizing outputs and minimizing inputs and its previous application in the related context of soybean pathways selections in Brazil, considering the transportation from farmers to ports, by Melo et al. (2018). It was decided to investigate the impact of returns to scale (CRS or VRS) in the results for the current application, to confirm the most appropriate approach for the particular problem. Hence, the differences between the results of both approaches were analysed in this study.

The SBM as proposed by Tone (2001) is expressed as follows in Equations (11) to (15):

$$
\begin{gathered}
\text { Minimize } \tau=\mathrm{t}-\left(\frac{1}{\mathrm{~m}}\right) \sum_{\mathrm{i}=1}^{\mathrm{m}} \frac{\mathrm{S}_{\mathrm{i}}^{-}}{\mathrm{x}_{\mathrm{i} 0}} \\
\left(\frac{1}{\mathrm{~s}}\right) \sum_{\mathrm{r}=1}^{\mathrm{s}} \frac{\mathrm{S}_{\mathrm{r}}^{+}}{\mathrm{y}_{\mathrm{r} 0}}+\mathrm{t}=1 \\
\sum_{\mathrm{i}=1}^{\mathrm{m}} \Lambda_{\mathrm{k}} \mathrm{x}_{\mathrm{ik}}+\mathrm{S}_{\mathrm{i}}^{-}-\mathrm{t} \mathrm{x}_{\mathrm{i} 0}=0 \mathrm{k}=1,2, \ldots, \mathrm{z} \\
\sum_{\mathrm{i}=1}^{\mathrm{m}} \Lambda_{\mathrm{k}} \mathrm{y}_{\mathrm{rk}}+\mathrm{S}_{\mathrm{r}}^{+}-\mathrm{ty} \mathrm{y}_{\mathrm{r} 0}=0 \mathrm{k}=1,2, \ldots, \mathrm{z} \\
\Lambda_{\mathrm{k}} \geq 0, \mathrm{~S}_{\mathrm{i}} \geq 0, \mathrm{~S}_{\mathrm{r}}^{+} \geq 0 \text { and } \mathrm{t}>0
\end{gathered}
$$

Where:

$\tau$ : is the efficiency.

$\mathrm{S}_{\mathrm{i}}^{-}$: is the slack of the $\mathrm{i}_{\text {th }}$ input.

$\mathrm{S}_{\mathrm{r}}^{+}$: is the slack of the $\mathrm{r}_{\text {th }}$ output.

$\Lambda_{\mathrm{k}}$ : is the contribution of the $\mathrm{k}_{\mathrm{th}}$ DMU to the analysed DMU.

$\mathrm{t}$ : is the model linearization factor.

$\mathrm{x}_{\mathrm{i} 0}$ : is the $\mathrm{i}_{\text {th }}$ input of the DMU under analysis.

$\mathrm{x}_{\mathrm{ik}}$ :is the $\mathrm{i}_{\mathrm{th}}$ input of the kth DMU. 
$\mathrm{y}_{\mathrm{rk}}:$ is the $\mathrm{r}_{\mathrm{th}}$ output of the kth DMU.

$\mathrm{m}$ : is the number of inputs.

$s:$ is the number of outputs.

$\mathrm{z}$ : is the number of DMUs.

When the application requires a VRS, it is necessary to add an additional restriction, according to the Equation (16).

$$
\sum_{\mathrm{k}=1}^{\mathrm{z}} \Lambda_{\mathrm{k}}=\mathrm{t}
$$

The optimum solution $\left(\rho^{*}, t^{*}, \Lambda_{k}^{*}, S_{i}^{-*}, S_{r}^{+*}\right)$ is described by the conditions in Equation (17):

$$
\rho^{*}=\tau^{*}, \lambda_{\mathrm{k}}^{*}=\frac{\Lambda_{\mathrm{k}}^{*}}{\mathrm{t}^{*}}, \mathrm{~s}_{\mathrm{i}}^{-*}=\frac{\mathrm{s}_{\mathrm{i}}^{*}}{\mathrm{t}^{*}}, \mathrm{~s}_{\mathrm{r}}^{+*}=\frac{\mathrm{S}_{\mathrm{r}}^{* *}}{\mathrm{t}^{*}}
$$

In this model, a DMU will be considered efficient when $\rho^{*}=1$.

\subsection{Robustness analysis: Super-efficiency}

The super-efficiency in DEA consists of an approach where a test DMU (or set of test DMUs) is not included in a reference set (Zhu, 2001). For example, an efficient DMU is excluded from the analysis and the resulting ranking is investigated. The super-efficiency approach was initially applied as a tie-breaking method, subsequently it was used as a technique for outlier's determination and, more recently, Mozaffari and Gerami (2012) and Zhu (2001) stated that super-efficiency is accepted as a technique for sensitivity analysis in DEA. This is an approach that can be used for the case where simultaneous proportional change is assumed in all inputs and outputs for a specific DMU under consideration. In this study, the superefficiency has been used to analyse the robustness of the DMU ranking, through sensitivity analysis.

The super-efficiency formulation adopted in this study is according to the creator of the SBM model (Tone, 2001), who proposed, in a subsequent paper (Tone, 2002), the superefficiency analysis in the linear form for SBM, according to Equation (18):

$$
\delta^{*}=\min \tau=\frac{1}{\mathrm{~m}} \sum_{\mathrm{i}=1}^{\mathrm{m}} \frac{\widetilde{\mathrm{x}_{\mathrm{i}}}}{\mathrm{x}_{\mathrm{i} 0}}
$$

Subject to Equations (19) to (24):

$$
\frac{1}{\mathrm{~s}} \sum_{\mathrm{r}=1}^{\mathrm{s}} \frac{\tilde{y}_{r}}{\mathrm{y}_{\mathrm{r} 0}}=1
$$




$$
\begin{gathered}
\tilde{x} \geq \sum_{\mathrm{k}=1, \neq 0}^{\mathrm{z}} \Lambda_{\mathrm{k}} \mathrm{x}_{\mathrm{k}} \\
\tilde{y} \leq \sum_{\mathrm{k}=1, \neq 0}^{\mathrm{z}} \Lambda_{\mathrm{k}} \mathrm{y}_{\mathrm{k}} \\
\widetilde{\mathrm{x}} \geq \mathrm{tx}_{0} \\
\tilde{\mathrm{y}} \leq \mathrm{ty}_{0} \\
\Lambda_{\mathrm{k}} \geq 0, \widetilde{\mathrm{x}} \geq 0, \tilde{\mathrm{y}} \geq 0 \text { and } \mathrm{t}>0
\end{gathered}
$$

Where:

$\delta^{*}:$ is the optimized super-efficiency score.

$\delta$ : is the super-efficiency score.

$\tilde{x}:$ is the linearized average of input expansion rate for the linear problem $(\tilde{x}=t \overline{\mathrm{x}})$.

$\tilde{y}$ : is the average output reduction rate for the linear problem $(\tilde{y}=t \bar{y})$.

$\overline{\mathrm{x}}:$ is the average input expansion rate.

$\overline{\mathrm{y}}:$ is the average output reduction rate.

The other elements are described in Equations (11) to (15).

The optimum solution $\left(\delta^{*}, \mathrm{t}^{*}, \lambda_{\mathrm{k}}^{*}, \bar{x}^{*}, \bar{y}^{*}\right)$ is described by the conditions in Equation $(25)$

$$
\delta^{*}=\tau^{*}, \lambda_{\mathrm{k}}^{*}=\frac{\Lambda_{\mathrm{k}}^{*}}{\mathrm{t}^{*}}, \bar{x}^{*}=\frac{\tilde{x}^{*}}{\mathrm{t}^{*}}, \bar{y}^{*}=\frac{\tilde{y}^{*}}{\mathrm{t}^{*}}
$$

\subsection{Tie-breaking method: Composite index}

Tie-breaking methods are methods used to re-rank the DMUs in a way that decreases the number of DMUs tied in the same position of the ranking.

In this study, the composite index method proposed by Leta et al. (2005) was applied as a tie-breaking. As it can be seen by Equation (26), the index represents an arithmetic average between standard and inverted efficiencies standardized by the maximum composite index of the analysed population.

$$
\mathrm{E}_{\mathrm{k}}^{\text {composite }}=\frac{\left[\mathrm{E}_{\mathrm{k}}^{\text {standard }}+\left(1-\mathrm{E}_{\mathrm{k}}^{\text {inverted }}\right)\right] / 2}{\left.\max \left\{\left[\mathrm{E}_{\mathrm{k}}^{\text {standard }}+\left(1-\mathrm{E}_{\mathrm{k}}^{\text {inverted }}\right)\right] / 2\right]\right\}} \mathrm{k}=1,2,3, \ldots, \mathrm{z}
$$

Where:

$\mathrm{E}_{\mathrm{k}}^{\text {standard }}$ : is the standard efficiency resulted from the application of the DEA model for the kth DMU. 
$E_{k}^{\text {inverted: }}$ is the inverted efficiency of the kth DMU, i.e., the resulted efficiency when inputs are inserted in SBM model as outputs and vice versa.

\section{Case study description}

Brazil is a country of continental dimensions with an area of above 8 million square kilometres (IBGE - Brazilian Institute of Geography and Statistics, 2019). The country is home to the second largest forest area in the world, corresponding to $54.4 \%$ of its territory (Ministry of Environment, 2013). Planted forest areas account for 7.8 million hectares, mainly consisting of Eucalyptus and Pinus, and are currently supplying mainly the sectors of pulp and paper, steel and charcoal production, timber investment management, laminated wood panels and solid wood products (Brazilian Tree Industry, 2016).

In addition to land availability, Brazil's favourable soil, climatic conditions and advanced technology in relation to forestry render the country as highly competitive in the international forest products market. Brazil has high productivity of planted trees, as it has the highest volume of wood produced per unit of area per year and the shortest rotation period in the world. In 2015, the average productivity of Eucalyptus plantations in Brazil was $36 \mathrm{~m}^{3} / \mathrm{ha}$ per year, compared to $10 \mathrm{~m}^{3} / \mathrm{ha}$ per year in Russia, Scandinavia and the Baltic Countries and 5 $\mathrm{m}^{3} /$ ha per year in Canada. The rotation period is 7 years in Brazil, while in Russia, Scandinavia, Baltic Countries and Canada it is over 30 years (Brazilian Tree Industry, 2016). Therefore, the potential of Brazil to supply biomass for various applications is significant.

The starting point in this study was to identify the range of options regarding the infrastructure and resources available in Brazil, including the locations of the main planted forests, the main exporting ports currently used by wood producers and the available modes of transportation to deliver wood from Brazilian forests to the UK.

According to the Brazilian Tree Industry (2016), eucalyptus plantations covered 5.6 million hectares of the area of planted trees in the country, and are mainly located in the states of Minas Gerais (MG) (24\%), São Paulo (SP) (17\%), and Mato Grosso do Sul (MS) (15\%). Pine plantations occupy 1.6 million hectares and are concentrated in Paraná (PR) (42\%) and in Santa Catarina (SC) (34\%). The choice of the biomass origin states to be considered in this study was guided by the states with the largest area of planted trees, considering Pinus and Eucalyptus as the dominant planted tree species. Additionally, the states that are currently the main wood exporters were added in the investigation, i.e. Rio Grande do Sul (RS) and Amapá (AP) (Ministry of Industry. Exterior Commerce and Services, 2016). 
The exporting ports included in this study were selected based on the criterion that they should currently handle some type of wood or biomass and can handle the size of ships considered for international shipping. Table 4 summarizes the ports included, followed by the respective United Nations Code for Trade and Transportation Logistics (UN/LOCODE) for providing a unique reference. The National Infrastructure of Spatial Data (2016) was consulted for determining inland routes and available modes of freight transportation from the main state forests up to the ports. The majority of alternatives were by road transportation, followed by rail.

Table 4 Summary of the exporting ports and their respective codes.

\begin{tabular}{ll}
\hline Wood Exporting Ports & UN/LOCODE \\
\hline Rio Grande & BR RIG \\
Santana & $B R$ SAN \\
Santos & $B R$ SSZ \\
São Francisco do Sul & $B R$ SFS \\
Paranaguá & $B R P N G$ \\
Itajaí & $B R I T J$ \\
Vitória & $B R$ VIX \\
Rio de Janeiro & $B R$ RIO \\
\hline
\end{tabular}

It was assumed that all scenarios supply biomass for electricity generation purposes in the UK. The details for the identified 56 DMUs (possible alternative supply chain pathways) are presented in Table 9 of the Appendix with details on the biomass origin location, port, and transportation means used for each case.

The 56 pathways (DMUs) were classified into four main supply chain scenarios, reflecting the main alternative supply chain structures in terms of stage sequence and biomass processing technologies. Each DMU received a code according to the scenario, W, P, Q, and $\mathrm{R}$, respectively for Scenario 1, 2, 3, and 4. The transportation is assumed by road for most of the DMUs, except for those DMUs with codes starting by A (“Alternative"). In these cases, transportation is assumed to be a combination of truck and train haulage.

All scenarios were modelled for $1 \mathrm{t}$ of black biomass (torrefied pellets) delivered at the final use destination (the UK). In Scenarios 1 and 2, wood logs and white pellets, respectively, are transported to the UK, where torrefaction is performed at the end user location. All scenarios assume unloading in the UK port of Immingham (GB IMM), which is one of the main ports handling biomass in the UK, and rail transportation up to the DRAX power plant in 
North Yorkshire, as a representative example of a UK large-scale biomass firing electricity generation facility. The four scenarios are shown in Figure 2 and explained below:

Scenario $1(\mathbf{W})$ : Biomass is extracted from Brazilian forests and sent to the UK in the form of logs. It is then transported to the end user location, where it is torrefied and pelletised (10 DMUs coded W and 10 DMUs coded AW).

Scenario 2 (P): Biomass is extracted from Brazilian forests, converted into white pellets in existing pelleting facilities in Brazil and transported to the exporting port. The existing pellet plant locations were identified from the national association of biomass producers (Brazilian Association of Industries of Biomass and Renewable Energy, 2016). The location of the main pellet plants limits the potential for rail transportation (10 DMUs coded $\mathrm{P}$ and 2 DMUs coded AP). The white pellets are then shipped to the UK and are torrefied and repelletised at the end user location.

Scenario $3(\mathbf{Q})$ : Building on Scenario 2, Scenario 3 considers a combined torrefaction and pelleting process at the location of the existing pelleting plants in Brazil. The output is black pellets that is transported to the exporting ports to be shipped to the UK (10 DMUs coded Q and 2 DMUs coded AQ).

Scenario $4(\mathbf{R})$ : In this scenario, wood is extracted, transported to existing pelleting plants, pelletized and transported to the Brazilian export ports. At the port, there is a centralized torrefaction facility where biomass is torrefied and re-pelletized. Subsequently, it is shipped to the UK (10 DMUs code R and 2 DMUs code AR). 


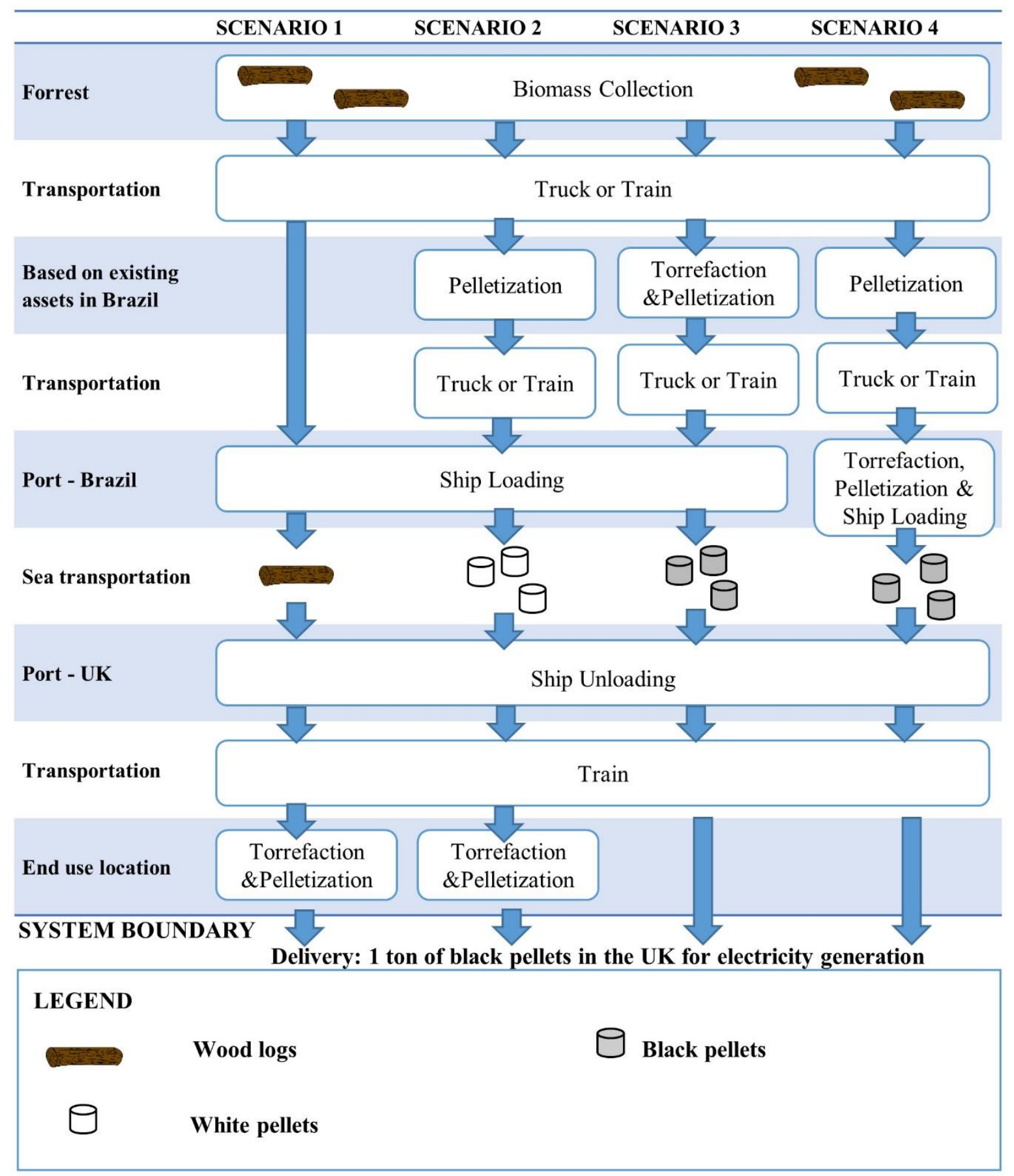

Figure 2 Schematic configuration of the supply chain pathways (scenarios).

\section{Results and discussion}

\subsection{Methodological discussions}

The efficiency results for all analysed cases are presented in Table 10 in the Appendix.

The results of efficient DMUs for the model with multiplicative inverted emissions (i.e., 1/emissions) as output (case 1) identified six efficient DMUs, while translated emissions 
(linearly transformed) as output (case 2) as well as emissions as input and using unitary output (case 3) identified seven efficient DMUs; the same six with case 1 plus the additional DMU AR2. This result is in accordance with Scheel (2001) who tested five ways of treating undesirable outputs and concluded that all efficient DMUs using the multiplicative inverse method (case 1) will be efficient in results compared to other approaches, but the inverse may not be valid, since the multiplicative inverse method distorts the efficiency frontier, due to the non-linear transformation. Ultimately, the outputs suggest seven equally efficient pathways, which indicates the necessity of applying a tie-breaking method for ranking the efficient pathways (section 5.4).

Considering the returns to scale, the efficiency results for SBM models (case 3) with a unitary output for all DMUs were the same independently of the type of returns to scale (CRS or VRS). To the best of the author's knowledge, there is no mathematical demonstration proving whether this is the case for all applications of unitary output without any exception. This could be a topic for further study in the DEA field.

As the results for unitary outputs were equal for both returns to scale approaches, from this point of the study onwards, only the SBM with unitary output and variable returns to scale (VRS assumption) will be discussed. It is worth noting that DEA as a multi-criteria tool can be understood as a "less-the-best" approach for inputs (Cook et al., 2014). In this way, modelling all three variables as inputs with a unitary output (which may also be interpreted as the output representing $1 \mathrm{t}$ of black pellets delivered at the end use destination) is aligned with the goals of the present application.

\subsection{Application results discussions}

Table 5 and Table 6 present respectively details of the most efficient and least efficient supply chain pathways.

Table 5 The most efficient DMUs, i.e. those with efficiency greater than 95\%.

\begin{tabular}{ccccc}
\hline Code & Origin & Mode & Port of destination & $\begin{array}{c}\text { Efficiency } \\
\text { SBM VRS } \\
\text { Unitary }\end{array}$ \\
\hline AQ2 & Lages (SC) & Rail & BR SFS & 1.0000 \\
R9 & Telêmaco Borba (PR) & Road & BR PNG & 1.0000 \\
AR2 & Lages (SC) & Rail & BR SFS & 1.0000
\end{tabular}




\begin{tabular}{ccccc} 
AW10 & Cataguases (MG) & Rail & BR VIX & 1.0000 \\
AW7 & Guarapuava (SC) & Rail & BR SFS & 1.0000 \\
W3 & Amapari (AP) & Road & BR SAN & 1.0000 \\
P9 & Telêmaco Borba (PR) & Road & BR PNG & 1.0000 \\
AW4 & Vespasiano (MG) & Rail & BR VIX & 0.9719 \\
R8 & Oiapoque (AP) & Road & BR SAN & 0.9534 \\
\hline
\end{tabular}

It is worth noting that among the seven highest efficiency cases, four are based on rail transportation. If cases with efficiency greater than $95 \%$ are considered, one additional DMU is based on rail transportation. This means that most of the efficient cases use rail transportation (Table 5), suggesting that even when the rail network is not adequate (and the cost is not minimal), these alternatives may still be efficient because of emissions and energy savings.

Focusing on the most inefficient cases (Table 6), only AP1 assumes rail transportation and it is combined with road transportation, while the others assume road transportation exclusively. This may be explained by the fact that, despite the losses of flexibility due to rail transportation, trains incur fewer emissions and less energy consumption for high volume freight.

Table 6 The 10 most inefficient DMUs.

\begin{tabular}{ccccc}
\hline Code & Origin & Mode & Port of destination & $\begin{array}{c}\text { Efficiency } \\
\text { SBM VRS } \\
\text { Unitary }\end{array}$ \\
& & & & \\
\hline P7 & Três Lagoas (MS) & Road & BR SFS & 0.3935 \\
Q7 & Três Lagoas (MS) & Road & BR SFS & 0.4285 \\
P2 & Bauru (SP) [6] & Road & BR SFS & 0.4602 \\
P3 & Encruzilhada do Sul (RS) & Road & BR RIG & 0.4688 \\
AP1 & Encruzilhada do Sul (RS) & Road + Rail & BR RIG & 0.4779 \\
P1 & Bauru (SP) & Road & BR SSZ & 0.4852 \\
P6 & Conceição da Barra (MG) & Road & BR RIO & 0.4973 \\
P10 & Telêmaco Borba (PR) & Road & BR PNG & 0.5025 \\
W6 & Três Lagoas (MS) & Road & BR SFS & 0.5028 \\
Q2 & Bauru (SP) & Road & BR SFS & 0.5099 \\
\hline
\end{tabular}

Among the most efficient, four cases belong to Scenario 1, three to Scenario 4, one case to Scenario 2, and one case to Scenario 3. The majority of efficient cases imply low-investment scenarios (mostly, Scenario 1) for decision-makers. Among the least efficient, seven cases belong to Scenario 2, one case to Scenario 1, one case to Scenario 3 and none to Scenario 4. In 
this regard, Scenario 2 would not be recommended for decision-makers, due to its dominant presence in the least efficient set. Figure 3 presents the visual and geographical representation of the results.

TOP EFFICIENT

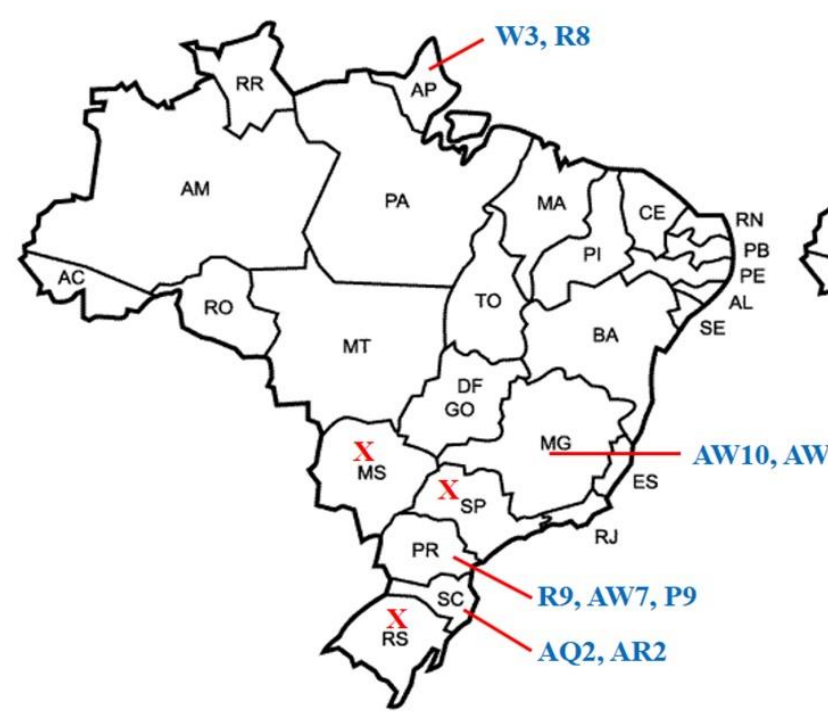

$\mathbf{X}$ : states without any top efficient DMU
LEAST EFFICIENT

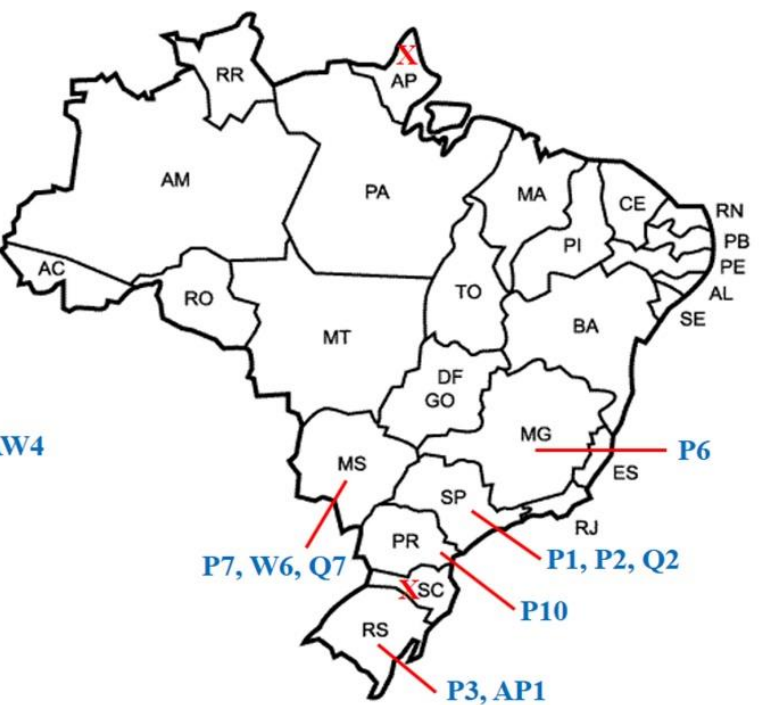

X: states without any least efficient DMU

Figure 3 Top and least efficient DMUs.

As can be seen in the left part of Figure 3, there is no DMU originating from SP, MS, and RS states among the most efficient. However, there are inefficient cases even considering alternative modes of transportation (AP1), even though these states are located nearer the ports. This may suggest to policy-makers that the existing rail network is not adequate for this demand. Among the least efficient, there is no DMU originating from SC and AP states at the right of Figure 3.

\subsection{Robustness analysis: super-efficiency}

All results of super-efficiency can be found in Table 11 in the Appendix. The percentage of increases in all inputs necessary to make an efficient DMU be deemed as inefficient is reflected in the super-efficiency value. The percentage of decrease in all inputs necessary to make an inefficient DMU be deemed as efficient is reflected in the efficiency value. For each analysed DMU, the results of the sensitivity analysis are the same independently of changes only in the values of DMU0 or if all DMUs (except DMU0) change the values equally. 
For efficient DMUs (efficiency=1), the super-efficiency will be a value equal or greater than 1 and it indicates the efficiency stability, i.e. how much a DMU can worsen its values (simultaneously) and still be efficient. For the inefficient DMUs, the super-efficiency will be equal to the efficiency with a value less than 1 . The sensitivity analysis using super-efficiency was performed accordingly to Zhu (2001). The results of the super-efficiency for the efficient DMUs only are presented in Table 7. According to Zhu (2001), the DMU with the highest super-efficiency value is considered to be the most stable.

Hence, AQ2 (Scenario 3 by rail) is the most stable DMU, as all input levels can increase simultaneously by up to $6.03 \%$ and it will still be efficient, followed by W3 (Scenario 1 by road), that could increase all input levels simultaneously by up to $6.01 \%$ and remain efficient. At the other extreme, the efficient DMU AW7 is the most sensitive to input changes, as only a $0.24 \%$ increase in all inputs could transform it into an inefficient DMU. Considering increases in input between $0.25 \%$ and 5\%, AW10 (Scenario 1 by rail), P9 (Scenario 2 by road), AR2 (Scenario 4 by rail), and R9 (Scenario 4 by road) could be easily transformed into inefficient DMUs. It can be concluded that most of the efficient solutions can easily become inefficient with small or moderate increases in the input values, and therefore the decision makers need also to consider the stability of the supply chain pathway they select. This is especially critical for scenarios that require long-term investment decisions, such as a new biomass processing facility.

Table 7 Super-efficiencies of the efficient DMUs.

\begin{tabular}{cccccr}
\hline Rank & Code & Origin & Mode & Port of destination & $\begin{array}{c}\text { Super- } \\
\text { efficiency }\end{array}$ \\
\hline 1 & $A Q 2$ & Lages (SC) & Rail & BR SFS & 1.0603 \\
2 & $W 3$ & Amapari (AP) & Road & BR SAN & 1.0601 \\
3 & $R 9$ & Telêmaco Borba (PR) & Road & BR PNG & 1.0491 \\
4 & $A R 2$ & Lages (SC) & Rail & BR SFS & 1.0214 \\
5 & $P 9$ & Telêmaco Borba (PR) & Road & BR PNG & 1.0128 \\
6 & $A W 10$ & Cataguases (MG) & Rail & BR VIX & 1.0061 \\
7 & $A W 7$ & Guarapuava (PR) & Rail & BR SFS & 1.0024 \\
\hline
\end{tabular}

A similar inverse logic applies for inefficient DMUs. The minimum value obtained is 0.3935 for DMU P7 (Scenario 2 by road), so it needs to decrease more than $60.65 \%$ its inputs to be efficient. After that amount, any inefficient DMU could be efficient. The percentage of change ((superefficiency-1) $100 \%)$ in all inputs simultaneously necessary to make efficient 
DMUs be inefficient (positive sign), or inefficient DMUs be efficient (negative sign), are presented in column 'Super-efficiency (\% change needed)' of Table 11 in the Appendix.

When examining the potential change of inefficient alternatives to efficient considering changes (decreases) in inputs between $0 \%$ and 5\%, AW4 and R8 could be easily changed to efficient. However, at least one efficient DMU will have all the three inputs value better (lower) than the DMUs under the $0 \%$ to $5 \%$ range of changes to be efficient, e.g. R9 has better input levels than R8 and AW10 has better input levels than AW4. In other words, it is possible to invest in the improvement of the efficiency of AW4 and R8, though they will not reach the optimal balance of the three inputs, as other alternatives cases will still perform better. Cases R9 and AW10 may be used for transportation until the limit of their efficiency (respectively, $4.91 \%$ and $0.61 \%$ as can be seen in Table 11) before considering investing on efficiency improvement of AW4 and R8.

\subsection{Tie-breaking: composite index}

The application of tie-breaking was necessary due to the seven cases of ties, in order to provide better understanding of the relative performance of the seven efficient pathways. The methodology proposed by Leta et al. (2005) was applied.

When comparing the seven DMUs originally identified as efficient (Table 5) with those top-ranked DMUs after tie-breaking (Table 8), six of the previous seven remain within the top 10 efficient (AQ2, W3, R9, AR2, AW10 and AW7). The new entrant in the top 10 is R5, which was previously within the top 15 highest efficiencies. On the other hand, P9 that was formerly considered efficient, dropped to $16^{\text {th }}$ position in the composite-index rank. All results of the tie-breaking process can be seen in Table 11 in the Appendix.

Table 8 The 16 highest efficient DMUs after composite index tie-breaking method.

\begin{tabular}{ccccr} 
Code & Origin & Mode & Port of destination & $\begin{array}{c}\text { Composite } \\
\text { Index }\end{array}$ \\
& & & & \\
\hline AQ2 & Lages (SC) & Rail & BR SFS & 1.0000 \\
R9 & Telêmaco Borba (PR) & Road & BR PNG & 0.9955 \\
AR2 & Lages (SC) & Rail & BR SFS & 0.9719 \\
R8 & Oiapoque (AP) & Road & BR SAN & 0.9644 \\
R4 & Canoinhas (SC) & Road & BR SFS & 0.9516 \\
R5 & Lages (SC) & Road & BR ITJ & 0.9492
\end{tabular}




\begin{tabular}{ccccc} 
AW10 & Cataguases (MG) & Rail & BR VIX & 0.9198 \\
AW7 & Guarapuava (SC) & Rail & BR SFS & 0.9176 \\
AW4 & Vespasiano (MG) & Rail & BR VIX & 0.9028 \\
W3 & Amapari (AP) & Road & BR SAN & 0.8840 \\
Q9 & Telêmaco Borba (PR) & Road & BR PNG & 0.8804 \\
R10 & Telêmaco Borba (PR) & Road & BR PNG & 0.8477 \\
R6 & Conceição da Barra (MG) & Road & BR RIO & 0.8406 \\
R1 & Bauru (SP) & Road & BR SSZ & 0.8289 \\
AW6 & Apucarana (PR) & Road + Rail & BR PNG & 0.8276 \\
P9 & Telêmaco Borba (PR) & Road & BR PNG & 0.8161 \\
\hline
\end{tabular}

Therefore, it can be concluded that the tie-breaking method has not led to major changes in the list of the most efficient solutions, apart from the case of P9. This DMU was the most negatively impacted among efficient DMUs, dropping 15 positions in the ranking due to its inverted efficiency result.

While the standard DEA frontier is used as a 'good' benchmark for DMUs, i.e., DMUs with the best practices are closer to it, the inverted efficiency frontier may be interpreted as a 'bad' benchmark, since the closest is a DMU to it, the worst its performance is expected to be. The benchmark for P9 (and for the most of the other DMUs) in the worst situation (inverted frontier) was P7. This can be seen by the value 1.000 for P7 in the column 'Inverted efficiency' of Table 11. P7 presents the greatest fuel consumption value among all DMUs, and this may be the cause of the negative impact represented by the inverted efficiency of $100 \%$.

P7 and P9 belong to the same Scenario 2 and are both unimodal; in this way, P9 is closer to P7 than the other DMUs. Consequently, it is more impacted negatively by the benchmarking (in the inverted frontier). According to Table 6, AQ2 is the most efficient DMU after tie-breaking (which is also the most stable DMU, according to super-efficiency analysis, and the DMU which has the smallest emissions value), followed by R9 (within a range of $1 \%$ and is the third most stable DMU, according to previous super-efficiency discussions).

\subsection{Implications for decision makers}

Assuming short-term decisions are those that can be effective for a period of time inferior to one year and medium-term decisions between one up to five years, Scenarios $1 \& 2$ can be assumed feasible in the short-term and $3 \& 4$ in the medium-term. This is because Scenarios $3 \& 4$ both consider the construction of a torrefaction facility in Brazil that requires significant investment, whereas Scenarios $1 \& 2$ make use of existing infrastructure in Brazil. Scenario 3 considers that the torrefaction facility will be constructed in conjunction with the 
current existing pellet facilities and Scenario 4 considers it will be constructed close to the exporting ports.

Among the most efficient, short and long-term investments cases are identified (Scenario 1 and 4), and long-term investments among the least efficient are rare (only one case for Scenario 3). This may suggest for decision makers to focus on medium-term investment in constructing torrefaction facilities closer to ports, where inefficient cases are less common. However, it should be mentioned that Scenario 1 cases assume the existence of torrefaction capability at the site of the end user in the UK, which may not necessarily be true and will depend on the actual case examined.

It is also important to emphasize that, although cultural and administrative strategic aspects are relevant for a medium-term investment strategic decision in a foreign country, they are not easily measurable and were not considered by the model. An interested reader in the theme, may benefit from consulting Ghemawat (2007).

In summary, results may direct decision and policy makers to conclude that:

- The decision on which pathway is the most efficient is not a straightforward one and needs the use of multi-criteria decision-making tools, such as the DEA method proposed in this study.

- Just the combination of biomass origin state and export port used is not enough to determine the efficient solutions: the choice of processing technology as well as the transportation route and mode also significantly affect the efficiency of the solution.

- Most efficient scenarios utilize rail transportation, although this is not always the case. This is an indication for policymakers that rail infrastructure investment should be considered if the biomass supply sector is to be expanded.

- $\quad$ The use of ports located in the same state as the biomass source location may not necessarily be a guarantee of efficiency.

The decision makers specifically interested in short-term investment strategies (focused on efficiency) should:

- Invest in importing biomass in wood $\operatorname{logs}$ as these cases tend to be more efficient overall.

- $\quad$ Prioritize states that have good infrastructure on rail network and where the biomass stocks are close to the exporting ports. Good rail infrastructure can allow more efficient transport of biomass over long distances in terms of energy use and emissions. 
For decision makers interested in medium-term investment strategies (focused on efficiency), the results may lead to the following directions:

- Investments in the construction of torrefaction facilities closer to the exporting ports tend to be more efficient.

- Investments in the construction of torrefaction facilities in the States of PR, SC, and AP tend to be more efficient.

\section{Conclusions}

This paper presented an application of the DEA method for assessing international biomass supply chain alternative pathways efficiency in a multi-criteria manner, in terms of cost, environmental impact (GHG emissions) and fossil energy input, while integrating also alternative modes of transportation where they exist. The method aims to facilitate decisions on selecting the most efficient supply chain design when decisions about sourcing biomass internationally are to be made.

It has been applied to the specific case study of international biomass transportation between Brazil and the UK. In this respect, 56 distinct supply chain pathways were examined, that have been clustered in four main scenarios, depending on the biomass processing technology used and the location of the processing facility along the supply chain. All scenarios include torrefaction of biomass at some stage of the chain. Alternative transportation routes and modes were also examined for the cases where this was an option. The SBM DEA model application has identified seven pathways as efficient DMUs due to a mix of performance against the three criteria. A tie-breaking method was also applied to support the identification of the most efficient pathway.

More specifically, the most efficient DMU after tie-breaking was AQ2, a supply chain pathway originating in Lages (SC) to the port of São Francisco do Sul (SC), using rail transport. This DMU belongs to scenario 3, where torrefaction and pelletisation are performed upstream in the supply chain, near the forests, transporting black pellets to the port. Also, AQ2 was found to be the most stable DMU during the robustness analysis. However, it was also found that the majority of the efficient pathways beyond AQ2 belong to scenario 1 (transporting wood logs to the UK and torrefying and pelletizing at the end user location), followed by scenario 4 (converting wood logs into white pellets near the forests and torrefying at the Brazilian export ports). Therefore, there is no clear preference on one scenario, indicating that the efficiency changes depending on the individual circumstances of each pathway examined. Overall, rail 
transportation is used in four out of the seven most efficient pathways, indicating a positive impact of rail transportation on all criteria examined. All efficient pathways originate from four Brazilian states out of the total seven investigated.

Furthermore, the robustness analysis proved that most efficient pathways are quite sensitive to changes in the input values; therefore, the decision makers need to consider also the stability of the chosen supply chain pathway in input changes alongside its efficiency. Ultimately, the decision on the best performing pathway depends on the priorities of the decision maker.

There are also several additional managerial and policy implications from the results of this study. Besides AQ2 from scenario 3 being the most efficient after tie-breaking, it was identified that it is not straightforward to come up with general rules on which processing technology or which transportation mode is the best to use; the optimal solution depends on a case-by-case basis, and therefore decision-making tools such as DEA need to be used to support this process.

The fact that most efficient scenarios were based on rail transport and most inefficient scenarios were based on road transport serves as an indication for policy makers in terms of infrastructure investment and decision makers in terms of sourcing area selection. Policy makers, in particular, can use the proposed model not only to examine existing routes but also to investigate the impact a new railway or the electrification of an existing one could have on the sector in terms of performance on emissions, cost, and fossil fuel use. The model presented points out the performance of each alternative pathway and therefore allows policy makers to prioritize the development of the sector and incentives to the most promising areas, depending on their efficiencies.

The study presented has several implications for researchers and academia too. Firstly, it expands the under researched field of DEA applications for decision making among multicriteria alternative supply chain scenarios. It is the first time DEA has been applied for multicriteria decision making, including environmental impact as one of the objectives, for the case of international biomass supply chains where several alternative supply pathways are possible, and therefore it contributes in offering new perspectives in this field. It is also the first research to investigate specifically the potential biomass supply chain between Brazil and the UK, therefore providing insights in the performance of the particular option that can be used for benchmarking purposes by other researchers. It has also added to the emerging discussion of the novel torrefaction processing technology by investigating the efficiency of its use in different supply chain stages. 
This study had some limitations apparent in research studies of similar nature. Although every effort was put to identify all reasonably possible supply chain pathways, there are more potential pathways that could be theoretically examined. However, most of these would be impractical in reality. Furthermore, the analysis was based on existing transportation infrastructure and did not include any planned expansion or investment in infrastructure that could potentially change the analysis results in the long-term.

The approach of identifying the performance of multiple cases instead of only the optimum one does have its merits, as in real life decision makers need to know about alternative options with relatively similar performance before making a decision, as there are many factors not included in the model that could eventually impact the decision, such as safety, existing commercial relationships or trading routes, environmental restrictions, investment incentives etc.

As a future research direction, it would be interesting to mathematically demonstrate whether a SBM model with a unitary output results in the same efficiency rank, independently of the scale. It is also interesting to develop a DEA-based approach that would facilitate the decision-making process by including the priorities of the decision maker in the process. Finally, for incorporating risks and uncertainty, AHP or Fuzzy logic may also be integrated into DEA models for investigating biomass supply chains in the future.

\section{Acknowledgements}

The authors would like to thank the Coordination for the Improvement of Higher Education Personnel (CAPES) and Foundation for Research Support of the State of São Paulo (FAPESP) for partially supporting this research study.

\section{References}

Adler, N., Golany, B., 2007. PCA-DEA, in: Modeling Data Irregularities and Structural Complexities in Data Envelopment Analysis. Springer US, Boston, MA, pp. 139-153. https://doi.org/10.1007/978-0-387-71607-7_8

Ahn, Y.-C., Lee, I.-B., Lee, K.-H., Han, J.-H., 2015. Strategic planning design of microalgae biomassto-biodiesel supply chain network: Multi-period deterministic model. Appl. Energy 154, 528542. https://doi.org/10.1016/J.APENERGY.2015.05.047

Babazadeh, R., Razmi, J., Rabbani, M., Pishvaee, M.S., 2015. An integrated data envelopment analysis-mathematical programming approach to strategic biodiesel supply chain network design problem. J. Clean. Prod. 147, 694-707. https://doi.org/10.1016/j.jclepro.2015.09.038 
Bacen - Central Bank of Brazil, 2019. Basic Interest Rate - History [WWW Document]. URL https://www.bcb.gov.br/controleinflacao/historicotaxasjuros (accessed 4.7.19).

Batidzirai, B., van der Hilst, F., Meerman, H., Junginger, M., Faaij, A., 2014. Optimization potential of biomass supply chains with torrefaction technology. Biofuels, Bioprod. Biorefining 8, 253 282. https://doi.org/10.1002/bbb.1458

Brander, M., Sood, A., Wylie, C., Haughton, A., Lovell, J., 2011. Electricity-specific emission factors for grid electricity.

Brazilian Association of Industries of Biomass and Renewable Energy, 2016. Pellets [WWW Document].

Brazilian Tree Industry, 2016. Annual Report - 2015 [WWW Document]. URL http://iba.org/images/shared/iba_2015.pdf

CEE Distribution, 2019. Rates and Costs of Service.

Cook, W.D., Tone, K., Zhu, J., 2014. Data envelopment analysis: Prior to choosing a model. Omega (United Kingdom) 44, 1-4. https://doi.org/10.1016/j.omega.2013.09.004

Damen, K., Faaij, A., 2006. A greenhouse gas balance of two existing international biomass import chains: The case of residue co-firing in a pulverised coal-fired power plant in the Netherlands. Mitig. Adapt. Strateg. Glob. Chang. 11, 1023-1050. https://doi.org/10.1007/s11027-006-9032-y

De Meyer, A., Cattrysse, D., Rasinmäki, J., Van Orshoven, J., 2014. Methods to optimise the design and management of biomass-for-bioenergy supply chains: A review. Renew. Sustain. Energy Rev. 31, 657-670. https://doi.org/10.1016/j.rser.2013.12.036

Department of Energy \& Climate Change, 2012. UK Bioenergy Strategy.

Department of Energy \& Climate Change, 2011. UK Renewable Energy Roadmap.

EcoTransIT, 2016. EcoTransIT [WWW Document].

EcoTransIT Methodology, 2014. Ecological Transport Information Tool for Worldwide Transports Methodology and Data Update IFEU Heidelberg INFRAS Berne IVE Hannover BerneHannover-Heidelberg, 4 th December 2014. Berne - Hannover - Heidelberg.

Ehrig, R., Behrendt, F., 2013. Co-firing of imported wood pellets - An option to efficiently save CO2 emissions in Europe? Energy Policy 59, 283-300. https://doi.org/10.1016/J.ENPOL.2013.03.060

European Commission, 2015. Renewable Energy Progress Report.

EuroStat, 2016. The EU in the world 2016 edition. https://doi.org/10.2785/745946

Ghemawat, P., 2007. Redefining global strategy : crossing borders in a world where differences still matter. Harvard Business School Press.

Government of Brazil, 2019. Employee costs go beyond salary [WWW Document]. URL http://www.brasil.gov.br/economia-e-emprego/2012/02/custos-com-empregado-vao-alem-dosalario (accessed 4.7.19).

Greco, S., Ishizaka, A., Tasiou, M., Torrisi, G., 2018. On the Methodological Framework of Composite Indices: A Review of the Issues of Weighting, Aggregation, and Robustness. Soc. 
Indic. Res. 1-34. https://doi.org/10.1007/s11205-017-1832-9

Grigoroudis, E., Petridis, K., Arabatzis, G., 2014. RDEA: A recursive DEA based algorithm for the optimal design of biomass supply chain networks. Renew. Energy 71, 113-122. https://doi.org/10.1016/j.renene.2014.05.001

Hamelinck, C.N., Suurs, R.A.A., Faaij, A.P.C., 2005. International bioenergy transport costs and energy balance. Biomass and Bioenergy 29, 114-134. https://doi.org/10.1016/j.biombioe.2005.04.002

How, B. shen, Lam, H.L., 2018. Sustainability evaluation for biomass supply chain synthesis: Novel principal component analysis (PCA) aided optimisation approach. J. Clean. Prod. 189, 941-961. https://doi.org/10.1016/J.JCLEPRO.2018.03.104

Hua, Z., Bian, Y., 2007. DEA with Undesirable Factors, in: Modeling Data Irregularities and Structural Complexities in Data Envelopment Analysis. Springer US, Boston, MA, pp. 103-121. https://doi.org/10.1007/978-0-387-71607-7_6

IBGE - Brazilian Institute of Geography and Statistics, 2019. Area of Districts [WWW Document]. URL https://www.ibge.gov.br/geociencias-novoportal/organizacao-do-territorio/estruturaterritorial/15761-areas-dos-municipios.html?=\&t=o-que-e (accessed 3.26.19).

Leta, F.R., Soares de Mello, J., Gomes, E.G., Angulo Meza, L., 2005. Métodos de melhora de ordenação em DEA aplicados à avaliação estática de tornos mecânicos. Investig. Operacional 25, 229-242.

Liu, W.B., Meng, W., Li, X.X., Zhang, D.Q., 2010. DEA models with undesirable inputs and outputs. Ann. Oper. Res. 173, 177-194. https://doi.org/10.1007/s10479-009-0587-3

Mafakheri, F., Nasiri, F., 2014. Modeling of biomass-to-energy supply chain operations: Applications, challenges and research directions. Energy Policy 67, 116-126. https://doi.org/10.1016/j.enpol.2013.11.071

Melo, I.C., Junior, P.N.A., Perico, A.E., Guzman, M.G.S., Rebelatto, D.A. do N., 2018. Benchmarking freight transportation corridors and routes with data envelopment analysis (DEA). Benchmarking An Int. J. 25, 713-742. https://doi.org/10.1108/BIJ-11-2016-0175

Ministry of Environment, 2013. Forests [WWW Document]. URL http://www.metadados.ibge.gov.br/consulta/default.aspx

Ministry of Industry. Exterior Commerce and Services, 2016. AliceWeb2 [WWW Document]. URL http://aliceweb.mdic.gov.br/

Mozaffari, M.R., Gerami, J., 2012. Super-Efficiency and Sensitivity AnalysisBased on Input-Oriented DEA-R. J. Math. Ext. 6.

National Infrastructure of Spatial Data, 2016. Geo Services. Map Viewer. Iterative Maps [WWW Document].

National Waterway Transportation Agency, 2017. Current rates [WWW Document].

Ng, W.P.Q., Lam, H.L., Yusup, S., 2013. Supply network synthesis on rubber seed oil utilisation as 
potential biofuel feedstock. Energy 55, 82-88. https://doi.org/10.1016/J.ENERGY.2013.02.036

Organisation for Economic Co-operation and Development (OECD)- European Commission, 2008.

Handbook on constructing composite indicators: methodology and user guide.

Qorri, A., Mujkić, Z., Kraslawski, A., 2018. A conceptual framework for measuring sustainability performance of supply chains. J. Clean. Prod. 189, 570-584.

https://doi.org/10.1016/j.jclepro.2018.04.073

Rentizelas, A.A., Li, J., 2016. Techno-economic and carbon emissions analysis of biomass torrefaction downstream in international bioenergy supply chains for co-firing. Energy 114. https://doi.org/10.1016/j.energy.2016.07.159

Scheel, H., 2001. Undesirable outputs in efficiency valuations. Eur. J. Oper. Res. 132, 400-410. https://doi.org/10.1016/S0377-2217(00)00160-0

Seiford, L.M., Zhu, J., 2002. Modeling undesirable factors in efficiency evaluation. Eur. J. Oper. Res. 142, 16-20. https://doi.org/10.1016/S0377-2217(01)00293-4

Sharifzadeh, M., Garcia, M.C., Shah, N., 2015. Supply chain network design and operation: Systematic decision-making for centralized, distributed, and mobile biofuel production using mixed integer linear programming (MILP) under uncertainty. Biomass and Bioenergy 81, 401414. https://doi.org/10.1016/j.biombioe.2015.07.026

SIFRECA - ESALQ-LOG, 2016. Freight Market [WWW Document].

Svanberg, M., Olofsson, I., Flodén, J., Nordin, A., 2013. Analysing biomass torrefaction supply chain costs. Bioresour. Technol. 142, 287-296. https://doi.org/10.1016/j.biortech.2013.05.048

ten Kate, J., Teunter, R., Kusumastuti, R.D., van Donk, D.P., 2017. Bio-diesel production using mobile processing units: A case in Indonesia. Agric. Syst. 152, 121-130.

Tone, K., 2003. Dealing with undesirable outputs in DEA: A slacks-based measure (SBM) approach. GRIPS Res. Rep. Ser. 44-45. https://doi.org/10.1007/978-1-4419-6151-8_8

Tone, K., 2002. A slacks-based measure of super-efficiency in data envelopment analysis. Eur. J. Oper. Res. 143, 32-41. https://doi.org/10.1016/S0377-2217(01)00324-1

Tone, K., 2001. A slacks-based measure of efficiency in data envelopment analysis. Eur. J. Oper. Res. 130, 498-509. https://doi.org/10.1016/S0377-2217(99)00407-5

Tree Functional Attributes and Ecological Database, 2019. ICRAF Database - Wood Density [WWW Document].

Uslu, A., Faaij, A.P.., Bergman, P.C.., 2008. Pre-treatment technologies, and their effect on international bioenergy supply chain logistics. Techno-economic evaluation of torrefaction, fast pyrolysis and pelletisation. Energy 33, 1206-1223. https://doi.org/10.1016/j.energy.2008.03.007

Worldwide Inflation Data, 2019. Inflation - up to date info on current and historic inflation by country [WWW Document]. Inflation.eu. URL https://www.inflation.eu/ (accessed 4.7.19).

Zhang, Y., Jiang, Y., 2016. Robust optimization on sustainable biodiesel supply chain produced from waste cooking oil under price uncertainty. Waste Manag. 
https://doi.org/10.1016/j.wasman.2016.11.004

Zhu, J., 2001. Super-efficiency and DEA sensitivity analysis. Eur. J. Oper. Res. 129, 443-455. https://doi.org/10.1016/S0377-2217(99)00433-6 


\section{Appendix}

Table 9 Data of DMUs.

\begin{tabular}{|c|c|c|c|c|c|c|}
\hline Code & District of origin (State) & $\begin{array}{l}\text { Freight } \\
\text { mode }\end{array}$ & Port of destination & $\begin{array}{l}\text { Total Cost up to UK } \\
\text { (US\$/delivered t) }\end{array}$ & $\begin{array}{c}\text { Energy Consumption (in } \\
\text { MJ/delivered t) }\end{array}$ & $\begin{array}{c}\text { Emissions (kg of } \\
\text { CO2eq/delivered t) }\end{array}$ \\
\hline$W 1$ & Encruzilhada do Sul (RS) & Road & BR RIG & 165.09 & $12,269.86$ & 396.75 \\
\hline$W 2$ & São Jorge do Oiapoque (AP) & Road & BR SAN & 177.22 & $15,524.94$ & 641.16 \\
\hline$W 3$ & Amapari (AP) & Road & BR SAN & 130.86 & $10,565.80$ & 269.73 \\
\hline W4 & Bauru (SP) & Road & BR SSZ & 179.03 & $13,263.13$ & 471.72 \\
\hline W5 & Bauru (SP) & Road & BR SFS & 178.07 & $15,298.39$ & 623.32 \\
\hline W6 & Três Lagoas (MS) & Road & BR SFS & 204.88 & $18,166.02$ & 839.48 \\
\hline$W 7$ & Conceição da Barra (MG) & Road & BR RIO & 160.48 & $12,760.53$ & 432.76 \\
\hline$W 8$ & Telêmaco Borba (PR) & Road & BR PNG & 156.18 & $12,605.05$ & 400.64 \\
\hline W9 & Canoinhas (SC) & Road & BR ITJ & 150.66 & $11,931.07$ & 370.63 \\
\hline$W 10$ & Lages (SC) & Road & BR SFS & 151.59 & $12,465.93$ & 410.20 \\
\hline$A W 1$ & Encruzilhada do Sul (RS) & Road + Rail & BR RIG & 180.13 & $11,808.07$ & 363.11 \\
\hline$A W 2$ & Três Lagoas (MS) & Rail & BR SFS & 216.45 & $9,477.55$ & 187.66 \\
\hline$A W 3$ & Três Lagoas (MS) & Rail & BR PNG & 214.30 & $9,475.09$ & 187.66 \\
\hline
\end{tabular}




\begin{tabular}{|c|c|c|c|c|c|c|}
\hline$A W 4$ & Vespasiano (MG) & Rail & BR VIX & 177.96 & $9,389.79$ & 179.92 \\
\hline AW5 & Telêmaco Borba (PR) & Road + Rail & BR PNG & 183.94 & $11,119.28$ & 312.63 \\
\hline$A W 6$ & Apucarana (PR) & Road + Rail & BR PNG & 173.67 & $10,020.82$ & 227.38 \\
\hline$A W 7$ & Guarapuava (PR) & Rail & BR SFS & 160.26 & $9,452.14$ & 184.76 \\
\hline$A W 8$ & Lages (SC) & Road + Rail & BR RIG & 224.33 & $12,227.04$ & 393.56 \\
\hline$A W 9$ & Lages (SC) & Road + Rail & BR SFS & 203.99 & $12,156.21$ & 388.74 \\
\hline$A W 10$ & Cataguases (MG) & Rail & BR VIX & 163.24 & $9,382.10$ & 179.92 \\
\hline$P 1$ & Bauru (SP) & Road & BR SSZ & 155.01 & $31,477.92$ & 477.80 \\
\hline$P 2$ & Bauru (SP) & Road & BR SFS & 159.94 & $33,080.05$ & 600.38 \\
\hline$P 3$ & Encruzilhada do Sul (RS) & Road & BR RIG & 159.74 & $32,201.18$ & 530.93 \\
\hline P4 & Canoinhas (SC) & Road & BR SFS & 126.08 & $29,458.75$ & 329.13 \\
\hline$P 5$ & Lages (SC) & Road & BR ITJ & 127.53 & $29,393.48$ & 321.92 \\
\hline P6 & Conceição da Barra (MG) & Road & BR RIO & 148.64 & $31,530.57$ & 481.25 \\
\hline$P 7$ & Três Lagoas (MS) & Road & BR SFS & 189.58 & $36,251.23$ & 838.72 \\
\hline$P 8$ & Amapari (AP) & Road & BR SAN & 122.50 & $29,247.76$ & 307.43 \\
\hline$P 9$ & Telêmaco Borba (PR) & Road & BR PNG & 120.23 & $28,658.22$ & 265.95 \\
\hline$P 10$ & Telêmaco Borba (PR) & Road & BR PNG & 146.47 & $31,464.81$ & 476.60 \\
\hline
\end{tabular}




\begin{tabular}{|c|c|c|c|c|c|c|}
\hline$A P 1$ & Encruzilhada do Sul (RS) & Road + Rail & BR RIG & 162.45 & $30,947.00$ & 439.58 \\
\hline$A P 2$ & Lages (SC) & Rail & BR SFS & 176.99 & $27,005.15$ & 144.36 \\
\hline$Q 1$ & Bauru (SP) & Road & BR SSZ & 166.84 & $23,406.09$ & 360.22 \\
\hline$Q 2$ & Bauru (SP) & Road & BR SFS & 168.53 & $24,291.19$ & 429.33 \\
\hline$Q 3$ & Encruzilhada do Sul (RS) & Road & BR RIG & 168.23 & $23,702.74$ & 381.82 \\
\hline$Q 4$ & Canoinhas (SC) & Road & BR SFS & 142.37 & $21,492.49$ & 219.43 \\
\hline$Q 5$ & Lages (SC) & Road & BR ITJ & 142.93 & $21,409.13$ & 211.10 \\
\hline$Q 6$ & Conceição da Barra (MG) & Road & BR RIO & 158.44 & $22,985.00$ & 328.21 \\
\hline$Q 7$ & Três Lagoas (MS) & Road & BR SFS & 199.00 & $27,550.05$ & 673.86 \\
\hline$Q 8$ & Oiapoque (AP) & Road & BR SAN & 141.83 & $21,529.81$ & 217.44 \\
\hline$Q 9$ & Telêmaco Borba (PR) & Road & BR PNG & 132.58 & $20,331.71$ & 129.23 \\
\hline$Q 10$ & Telêmaco Borba (PR) & Road & BR PNG & 162.76 & $23,559.36$ & 371.97 \\
\hline$A Q 1$ & Encruzilhada do Sul (RS) & Road + Rail & BR RIG & 176.93 & $23,173.15$ & 345.08 \\
\hline$A Q 2$ & Lages (SC) & Rail & BR SFS & 197.04 & $19,265.76$ & 52.27 \\
\hline$R 1$ & Bauru (SP) & Road & BR SSZ & 168.87 & $16,733.33$ & 93.47 \\
\hline$R 2$ & Bauru (SP) & Road & BR SFS & 177.44 & $18,327.42$ & 102.04 \\
\hline$R 3$ & Encruzilhada do Sul (RS) & Road & BR RIG & 174.19 & $17,432.48$ & 98.79 \\
\hline
\end{tabular}




\begin{tabular}{|c|c|c|c|c|c|c|}
\hline$R 4$ & Canoinhas (SC) & Road & BR SFS & 143.59 & $14,706.13$ & 68.19 \\
\hline$R 5$ & Lages (SC) & Road & BR ITJ & 144.27 & $14,640.85$ & 68.87 \\
\hline$R 6$ & Conceição da Barra (MG) & Road & BR RIO & 165.18 & $16,794.02$ & 89.78 \\
\hline$R 7$ & Três Lagoas (MS) & Road & BR SFS & 207.09 & $21,498.60$ & 131.69 \\
\hline$R 8$ & Oiapoque (AP) & Road & BR SAN & 141.36 & $14,567.46$ & 65.96 \\
\hline$R 9$ & Telêmaco Borba (PR) & Road & BR PNG & 137.12 & $13,905.59$ & 61.72 \\
\hline$R 10$ & Telêmaco Borba (PR) & Road & BR PNG & 163.36 & $16,712.19$ & 87.96 \\
\hline$A R 1$ & Encruzilhada do Sul (RS) & Road + Rail & BR RIG & 175.65 & $16,160.29$ & 100.25 \\
\hline$A R 2$ & Lages (SC) & Rail & BR SFS & 160.33 & $12,232.64$ & 84.93 \\
\hline
\end{tabular}


Table 10 Results of efficiency for different scales and undesirable output configurations.

\begin{tabular}{|c|c|c|c|c|}
\hline Code & $\begin{array}{c}\text { Efficiency } \\
\text { SBM VRS } \\
\text { Inverted emissions } \\
\text { (i.e., 1/emissions) }\end{array}$ & $\begin{array}{c}\text { Efficiency } \\
\text { SBM CRS } \\
\text { Unitary }\end{array}$ & $\begin{array}{c}\text { Efficiency } \\
\text { SBM VRS } \\
\text { Unitary }\end{array}$ & $\begin{array}{c}\text { Efficiency } \\
\text { SBM VRS } \\
\text { Translated } \\
\text { emissions (i.e., } \\
\text { value - } \\
\text { emissions) }\end{array}$ \\
\hline$W 1$ & 0.1932 & 0.7170 & 0.7170 & 0.5935 \\
\hline$W 2$ & 0.0806 & 0.5886 & 0.5886 & 0.2520 \\
\hline W3 & 1.0000 & 1.0000 & 1.0000 & 1.0000 \\
\hline W4 & 0.1294 & 0.6510 & 0.6510 & 0.4614 \\
\hline W5 & 0.0834 & 0.5927 & 0.5927 & 0.2715 \\
\hline$W 6$ & 0.0529 & 0.5028 & 0.5028 & 0.0452 \\
\hline$W 7$ & 0.1627 & 0.7024 & 0.7024 & 0.5437 \\
\hline$W 8$ & 0.1835 & 0.7216 & 0.7216 & 0.5941 \\
\hline$W 9$ & 0.2324 & 0.7638 & 0.7638 & 0.6647 \\
\hline$W 10$ & 0.1868 & 0.7338 & 0.7338 & 0.5953 \\
\hline$A W 1$ & 0.2237 & 0.7165 & 0.7165 & 0.6234 \\
\hline$A W 2$ & 0.8062 & 0.8985 & 0.8985 & 0.8626 \\
\hline$A W 3$ & 0.8105 & 0.9012 & 0.9012 & 0.8664 \\
\hline$A W 4$ & 0.9554 & 0.9719 & 0.9719 & 0.9582 \\
\hline$A W 5$ & 0.3045 & 0.7544 & 0.7544 & 0.7009 \\
\hline$A W 6$ & 0.5970 & 0.8780 & 0.8780 & 0.8749 \\
\hline$A W 7$ & 1.0000 & 1.0000 & 1.0000 & 1.0000 \\
\hline$A W 8$ & 0.1720 & 0.6409 & 0.6409 & 0.5232 \\
\hline$A W 9$ & 0.1838 & 0.6660 & 0.6660 & 0.5521 \\
\hline$A W 10$ & 1.0000 & 1.0000 & 1.0000 & 1.0000 \\
\hline$P 1$ & 0.0860 & 0.4852 & 0.4852 & 0.3307 \\
\hline$P 2$ & 0.0659 & 0.4602 & 0.4602 & 0.2243 \\
\hline$P 3$ & 0.0753 & 0.4688 & 0.4688 & 0.2804 \\
\hline$P 4$ & 0.3389 & 0.7975 & 0.7975 & 0.7267 \\
\hline P5 & 0.2998 & 0.7700 & 0.7700 & 0.7015 \\
\hline$P 6$ & 0.0877 & 0.4973 & 0.4973 & 0.3372 \\
\hline$P 7$ & 0.0409 & 0.3935 & 0.3935 & 0.0354 \\
\hline$P 8$ & 0.5725 & 0.8959 & 0.8959 & 0.8551 \\
\hline$P 9$ & 1.0000 & 1.0000 & 1.0000 & 1.0000 \\
\hline P10 & 0.0896 & 0.5025 & 0.5025 & 0.3446 \\
\hline$A P 1$ & 0.0911 & 0.4779 & 0.4779 & 0.3523 \\
\hline$A P 2$ & 0.2757 & 0.5724 & 0.5724 & 0.5806 \\
\hline
\end{tabular}




\begin{tabular}{|c|c|c|c|c|}
\hline$Q 1$ & 0.1216 & 0.5291 & 0.5291 & 0.4534 \\
\hline$Q 2$ & 0.0999 & 0.5099 & 0.5099 & 0.3861 \\
\hline$Q 3$ & 0.1138 & 0.5211 & 0.5211 & 0.4306 \\
\hline$Q 4$ & 0.2269 & 0.6305 & 0.6305 & 0.6521 \\
\hline$Q 5$ & 0.2353 & 0.6337 & 0.6337 & 0.6597 \\
\hline$Q 6$ & 0.1386 & 0.5528 & 0.5528 & 0.4992 \\
\hline$Q 7$ & 0.0549 & 0.4285 & 0.4285 & 0.1567 \\
\hline$Q 8$ & 0.2293 & 0.6322 & 0.6322 & 0.6551 \\
\hline$Q^{9}$ & 0.5644 & 0.9271 & 0.9271 & 0.9188 \\
\hline$Q 10$ & 0.1194 & 0.5329 & 0.5329 & 0.4486 \\
\hline$A Q 1$ & 0.1232 & 0.5180 & 0.5180 & 0.4528 \\
\hline$A Q 2$ & 1.0000 & 1.0000 & 1.0000 & 1.0000 \\
\hline$R 1$ & 0.5418 & 0.7678 & 0.7678 & 0.7901 \\
\hline$R 2$ & 0.4609 & 0.7121 & 0.7121 & 0.7286 \\
\hline$R 3$ & 0.4963 & 0.7365 & 0.7365 & 0.7570 \\
\hline$R 4$ & 0.8539 & 0.9352 & 0.9352 & 0.9428 \\
\hline$R 5$ & 0.8537 & 0.9321 & 0.9321 & 0.9419 \\
\hline$R 6$ & 0.5711 & 0.7819 & 0.7819 & 0.8010 \\
\hline$R 7$ & 0.3074 & 0.5925 & 0.5925 & 0.5993 \\
\hline$R 8$ & 0.9040 & 0.9534 & 0.9534 & 0.9574 \\
\hline$R 9$ & 1.0000 & 1.0000 & 1.0000 & 1.0000 \\
\hline$R 10$ & 0.5888 & 0.7910 & 0.7910 & 0.8093 \\
\hline$A R 1$ & 0.5037 & 0.7523 & 0.7523 & 0.7825 \\
\hline AR2 & 0.9222 & 1.0000 & 1.0000 & 1.0000 \\
\hline
\end{tabular}

Table 11 Results of efficiency, composite index (and its elements), super-efficiency and ranking for the adopted model, SBM with variable scale, inputs: costs, energy and emissions, and unitary output.

\begin{tabular}{ccccccccc}
\hline Code & $\begin{array}{c}\text { Efficiency } \\
\text { SBM VRS } \\
\text { Unitary }\end{array}$ & $\begin{array}{c}\text { Inv. } \\
\text { Efficiency }\end{array}$ & $\begin{array}{c}\text { 1-Inv. } \\
\text { Efficiency }\end{array}$ & $\begin{array}{c}\text { Average } \\
\text { (Composite } \\
\text { Index) }\end{array}$ & $\begin{array}{c}\text { Composite } \\
\text { Index } \\
\text { standardized }\end{array}$ & $\begin{array}{c}\text { Super- } \\
\text { efficiency }\end{array}$ & $\begin{array}{c}\text { Super- } \\
\text { efficiency } \\
\text { (\%) } \\
\text { change } \\
\text { needed) }\end{array}$ & $\begin{array}{c}\text { Composite } \\
\text { Ranking }\end{array}$ \\
\hline$W 1$ & 0.7170 & 0.4826 & 0.5174 & 0.6172 & 0.6717 & 0.7170 & -28.30 & 28 \\
$W 2$ & 0.5886 & 0.6365 & 0.3635 & 0.4761 & 0.5181 & 0.5886 & -41.14 & 41 \\
$W 3$ & 1.0000 & 0.3755 & 0.6245 & 0.8123 & 0.8840 & 1.0601 & 6.01 & 10 \\
$W 4$ & 0.6510 & 0.5386 & 0.4614 & 0.5562 & 0.6054 & 0.6510 & -34.90 & 37 \\
$W 5$ & 0.5927 & 0.6276 & 0.3724 & 0.4826 & 0.5252 & 0.5927 & -40.73 & 40 \\
$W 6$ & 0.5028 & 1.0000 & 0.0000 & 0.2514 & 0.2736 & 0.5028 & -49.72 & 54
\end{tabular}




\begin{tabular}{|c|c|c|c|c|c|c|c|}
\hline$W 7$ & 0.7024 & 0.5033 & 0.4967 & 0.5996 & 0.6525 & 0.7024 & -29.76 \\
\hline$W 8$ & 0.7216 & 0.4852 & 0.5148 & 0.6182 & 0.6728 & 0.7216 & -27.84 \\
\hline W9 & 0.7638 & 0.4573 & 0.5427 & 0.6533 & 0.7110 & 0.7638 & -23.62 \\
\hline W10 & 0.7338 & 0.4836 & 0.5164 & 0.6251 & 0.6803 & 0.7338 & -26.62 \\
\hline$A W 1$ & 0.7165 & 0.4664 & 0.5336 & 0.6251 & 0.6803 & 0.7165 & -28.35 \\
\hline$A W 2$ & 0.8985 & 0.5353 & 0.4647 & 0.6816 & 0.7418 & 0.8985 & -10.15 \\
\hline$A W 3$ & 0.9012 & 0.5054 & 0.4946 & 0.6979 & 0.7596 & 0.9012 & -9.88 \\
\hline$A W 4$ & 0.9719 & 0.3129 & 0.6871 & 0.8295 & 0.9028 & 0.9719 & -2.81 \\
\hline$A W 5$ & 0.7544 & 0.4302 & 0.5698 & 0.6621 & 0.7206 & 0.7544 & -24.56 \\
\hline$A W 6$ & 0.8780 & 0.3572 & 0.6428 & 0.7604 & 0.8276 & 0.8780 & -12.20 \\
\hline$A W 7$ & 1.0000 & 0.3139 & 0.6861 & 0.8431 & 0.9176 & 1.0024 & 0.24 \\
\hline$A W 8$ & 0.6409 & 1.0000 & 0.0000 & 0.3205 & 0.3488 & 0.6409 & -35.91 \\
\hline$A W 9$ & 0.6660 & 0.6192 & 0.3808 & 0.5234 & 0.5697 & 0.6660 & -33.40 \\
\hline$A W 10$ & 1.0000 & 0.3097 & 0.6903 & 0.8452 & 0.9198 & 1.0061 & 0.61 \\
\hline$P 1$ & 0.4852 & 0.7264 & 0.2736 & 0.3794 & 0.4129 & 0.4852 & -51.48 \\
\hline$P 2$ & 0.4602 & 0.8156 & 0.1844 & 0.3223 & 0.3508 & 0.4602 & -53.98 \\
\hline$P 3$ & 0.4688 & 0.7708 & 0.2292 & 0.3490 & 0.3798 & 0.4688 & -53.12 \\
\hline$P 4$ & 0.7975 & 0.5679 & 0.4321 & 0.6148 & 0.6691 & 0.7975 & -20.25 \\
\hline P5 & 0.7700 & 0.5634 & 0.4366 & 0.6033 & 0.6566 & 0.7700 & -23.00 \\
\hline P6 & 0.4973 & 0.7198 & 0.2802 & 0.3888 & 0.4231 & 0.4973 & -50.27 \\
\hline$P 7$ & 0.3935 & 1.0000 & 0.0000 & 0.1968 & 0.2141 & 0.3935 & -60.65 \\
\hline$P 8$ & 0.8959 & 0.5440 & 0.4560 & 0.6760 & 0.7357 & 0.8959 & -10.41 \\
\hline$P 9$ & 1.0000 & 0.5004 & 0.4996 & 0.7498 & 0.8161 & 1.0128 & 1.28 \\
\hline P10 & 0.5025 & 0.7132 & 0.2868 & 0.3947 & 0.4295 & 0.5025 & -49.75 \\
\hline$A P 1$ & 0.4779 & 0.7065 & 0.2935 & 0.3857 & 0.4198 & 0.4779 & -52.21 \\
\hline$A P 2$ & 0.5724 & 0.3648 & 0.6352 & 0.6038 & 0.6572 & 0.5724 & -42.76 \\
\hline$Q 1$ & 0.5291 & 0.5984 & 0.4016 & 0.4654 & 0.5065 & 0.5291 & -47.09 \\
\hline$Q 2$ & 0.5099 & 0.6563 & 0.3437 & 0.4268 & 0.4645 & 0.5099 & -49.01 \\
\hline$Q 3$ & 0.5211 & 0.6182 & 0.3818 & 0.4515 & 0.4913 & 0.5211 & -47.89 \\
\hline$Q 4$ & 0.6305 & 0.4386 & 0.5614 & 0.5960 & 0.6486 & 0.6305 & -36.95 \\
\hline$Q 5$ & 0.6337 & 0.4290 & 0.5710 & 0.6024 & 0.6556 & 0.6337 & -36.63 \\
\hline$Q 6$ & 0.5528 & 0.5629 & 0.4371 & 0.4950 & 0.5387 & 0.5528 & -44.72 \\
\hline$Q 7$ & 0.4285 & 0.9522 & 0.0478 & 0.2382 & 0.2592 & 0.4285 & -57.15 \\
\hline$Q 8$ & 0.6322 & 0.4362 & 0.5638 & 0.5980 & 0.6508 & 0.6322 & -36.78 \\
\hline$Q^{9}$ & 0.9271 & 0.3092 & 0.6908 & 0.8090 & 0.8804 & 0.9271 & -7.29 \\
\hline$Q 10$ & 0.5329 & 0.6050 & 0.3950 & 0.4640 & 0.5050 & 0.5329 & -46.71 \\
\hline$A Q 1$ & 0.5180 & 0.5921 & 0.4079 & 0.4630 & 0.5039 & 0.5180 & -48.20 \\
\hline
\end{tabular}




\begin{tabular}{ccccccccc}
$A Q 2$ & 1.0000 & 0.1624 & 0.8376 & 0.9188 & 1.0000 & 1.0603 & 6.03 & 1 \\
$R 1$ & 0.7678 & 0.2447 & 0.7553 & 0.7616 & 0.8289 & 0.7678 & -23.22 & 14 \\
$R 2$ & 0.7121 & 0.2663 & 0.7337 & 0.7229 & 0.7868 & 0.7121 & -28.79 & 19 \\
$R 3$ & 0.7365 & 0.2573 & 0.7427 & 0.7396 & 0.8050 & 0.7365 & -26.35 & 18 \\
$R 4$ & 0.9352 & 0.1865 & 0.8135 & 0.8744 & 0.9516 & 0.9352 & -6.48 & 5 \\
$R 5$ & 0.9321 & 0.1879 & 0.8121 & 0.8721 & 0.9492 & 0.9321 & -6.79 & 6 \\
$R 6$ & 0.7819 & 0.2372 & 0.7628 & 0.7724 & 0.8406 & 0.7819 & -21.81 & 13 \\
$R 7$ & 0.5925 & 0.4171 & 0.5829 & 0.5877 & 0.6396 & 0.5925 & -40.75 & 36 \\
$R 8$ & 0.9534 & 0.1813 & 0.8187 & 0.8861 & 0.9644 & 0.9534 & -4.66 & 4 \\
$R 9$ & 1.0000 & 0.1707 & 0.8293 & 0.9147 & 0.9955 & 1.0491 & 4.91 & 2 \\
$R 10$ & 0.7910 & 0.2332 & 0.7668 & 0.7789 & 0.8477 & 0.7910 & -20.90 & 12 \\
$A R 1$ & 0.7523 & 0.2567 & 0.7433 & 0.7478 & 0.8139 & 0.7523 & -24.77 & 17 \\
AR2 & 1.0000 & 0.2140 & 0.7860 & 0.8930 & 0.9719 & 1.0214 & 2.14 & 3 \\
\hline
\end{tabular}

